\title{
InSPEÇÃo SANitária EM CRECHES: Uma Proposta de Roteiro de InsPeção
}

\author{
SANITARY INSPECTION IN DAYCARE CENTERS: \\ PROPOSING A GUIDELINE FOR INSPECTION
}

Vera Alice Elias da Silva ${ }^{(*)}$
Maria Helena Matte ${ }^{(* *)}$

\section{RESUMO}

O trabalho apresenta um projeto de intervenção na realidade concreta das ações de Vigilância Sanitária, através da proposição de um roteiro para inspeção destinado a creches. Os objetivos específicos foram identificar os fundamentos jurídicos, técnico-científicos e sanitários que possam nortear a prática de inspeções sanitárias em creches; elaborar uma proposta de roteiro que permita um processo de análise mais explícito, objetivo e homogêneo e discutir a contribuição do instrumento proposto para a atividade de Vigilância Sanitária, com base na literatura científica pesquisada. Para a realização do trabalho foi feita uma revisão fundamentada em textos didáticos e normativos das áreas de educação e saúde, legislação sobre Vigilância Sanitária e Educação Infantil, outros roteiros já existentes e artigos da literatura científica sobre agravos à saúde em crianças que frequentam creches. O trabalho focaliza o conteúdo da legislação específica vigente e sua aplicabilidade na prática da inspeção sanitária em creches e baseia-se na Portaria - MS n. 321 de 26.05.1988. Este estudo apresenta um instrumento para avaliar a qualidade do atendimento nas creches sob o aspecto da promoção da saúde e sugere estudos posteriores de validação para o contexto, com a possível inclusão de um sistema de classificação para os padrões de conformidade, por meio de uma metodologia estatística.

(*) Médica do Serviço de Vigilância Sanitária - Coordenadoria de Vigilância à Saúde — Secretaria Municipal de Saúde - Prefeitura do Município de Diadema, São Paulo, Brasil.

$\left.{ }^{(*}\right)$ Professora Associada da Faculdade de Saúde Pública, Universidade de São Paulo. E-mail: $<$ rmhmatte@usp.br>. Recebido em 24.6.08. Reapresentado em 30.3.09. Aprovado em 1.4.09. 


\title{
Palavras-chave
}

Creches; Inspeção Sanitária; Legislação Sanitária; Promoção da Saúde; Vigilância sanitária.

\begin{abstract}
This work presents a project of intervention in the reality of sanitary surveillance actions, through the proposition of an inspection guideline destined to daycare centers. The specific objectives were to identify the legal, technical-scientific and sanitary fundaments that can guide the practice of the sanitary inspections in daycare centers; to elaborate a proposal of a guideline that allows an objective, homogeneous and more explicit process of analysis and to discuss the contribution of the instrument proposed for the activity of sanitary surveillance, based on the researched scientific literature. For the accomplishment of this work it was made a revision based on health and educational scientific and normative texts and on the legislation of sanitary surveillance and childhooh education, on other existing guidelines and on scientific papers about health risks of children who attends daycare centers. This study is focused in the content of specific legislation and its applicability in the sanitary inspection practices in daycare centers and it is based on a legal document of the Brazilian Health Ministry (Portaria MS n. 321 of 26.05.1988). This work also presents a tool to evaluate the service quality in the daycare centers under the aspect of the health promotion and suggests posterior studies to validate the context, with possible inclusion of a classification system for the conformity standards, using statistical methodology.
\end{abstract}

\section{Keywords}

Daycare; Health Promotion; Sanitary Inspection; Sanitary Legislation; Sanitary Surveillance.

\section{INTRODUÇÃO}

Todo o processo de regulamentação da educação infantil no Brasil evidencia uma contradição entre o caráter educativo e o caráter assistencial desse serviço, pois acena de um lado com a legislação no âmbito da educação e de outro com a concretização no âmbito da assistência social(1).

(1) MORO C. S. As concepções sobre o sistema público de educação infantil de mães que utilizam e que não utilizam creches. UFPR, 2004. Disponível em: <http://www.anped.org.br/reunioes/27/ gt07/t071.pd>. Acesso em: 15 out. 2007. 
Nascida em nosso meio, como instituição para cuidar das crianças de mulheres que trabalhavam fora, a creche incorporou a imagem de assistencialista, mais tarde reforçada pela influência direta do pensamento médico. Não havia exigências sobre a formação dos profissionais que atuavam com as crianças, nem preocupações de ordem educacional que norteassem as atividades desenvolvidas.

Apesar de todo o avanço legal nessa área, em particular a Lei de Diretrizes e Bases de 1996, que concedeu três anos para as creches integrarem-se ao respectivo sistema de ensino (art. 89), grande parte delas ainda permanece no âmbito e sob a administração do setor de assistência social. Para que os avanços não se restrinjam ao papel e sejam realmente efetivados, há desafios a serem vencidos, tais como: aperfeiçoar a formação dos profissionais que atuam com crianças dessa faixa etária; eliminar a dependência das definições das prioridades de investimento para esta etapa de ensino ao que a política econômica disponibiliza; criar financiamento específico para a educação infantil; rever a política de convênios com instituições, em geral religiosas, que já trabalham com crianças de zero a seis anos, entre outros.

A educação da criança de quatro a seis anos se insere nas ações do atual Ministério da Educação (MEC) desde 1975 (então Ministério da Educação e Cultura), quando foi criada a Coordenação de Educação Pré-Escolar. $\mathrm{Na}$ área da Assistência Social do Governo Federal, outro órgão também se incumbia do atendimento ao "pré-escolar" por meio de programa desenvolvido pela Legião Brasileira de Assistência (LBA) do então Ministério da Previdência e Assistência Social, desde 1977. Conforme destaca Alves:

No Brasil, somente com a Constituição Federal de 1988, como fruto da luta de entidades civis organizadas em defesa dos direitos da infância, legitimou-se a educação infantil enquanto direito da criança. É a partir desse direito proclamado que se faz necessária a demarcação de algumas especificidades da educação de crianças de 0 a 6 anos ${ }^{(2)}$.

O Estatuto da Criança e do Adolescente - $\mathrm{ECA}^{(3)}$ reafirmou esse direito estabelecendo dispositivo legal para exigência do mesmo. A Educação Infantil deixava de se constituir em caridade para se transformar, ainda que apenas legalmente, em obrigação do Estado e direito da criança.

Desde então, foram deflagradas muitas discussões capitaneadas pelo MEC, que culminaram com a promulgação da Lei de Diretrizes e Bases LDB, que definiu a finalidade da educação infantil como: "o desenvolvimento integral da criança até 6 anos de idade, em seus aspectos físico, psicológico,

(2) ALVES, R. C. P. Percepções de educadoras e proposta institucional acerca dos cuidados infantis de saúde em creche. 2006. 93 p. Dissertação (Mestrado). Escola de Enfermagem da Universidade de São Paulo, São Paulo, 2006. p. 14.

(3) BRASIL. Lei n. 8.069, de 13 de julho de 1990. Dispõe sobre o Estatuto da Criança e do Adolescente, e dá outras providências. Diário Oficial da União, Brasília, DF, 16 jul. 1990. p. 92. 
intelectual e social, complementando a ação da família e da comunidade"(4). Uma série de documentos legais foram produzidos com o objetivo de definir critérios de qualidade para infraestrutura das unidades destinadas à educação da criança de zero a seis anos. Entretanto, particularmente nesse aspecto ainda há sérios problemas a serem superados, conforme o diagnóstico apresentado no Plano Nacional de Educação(5).

A educação infantil, constituindo um capítulo desse plano, teve seu horizonte de expansão e melhoria definido como obrigação dos sistemas de ensino da União, dos Estados, do Distrito Federal e dos Municípios. Em coerência com esse processo histórico, político e técnico, o MEC estabeleceu a Política Nacional de Educação Infantil de 2006 com suas diretrizes, objetivos, metas e estratégias. Publicou, no mesmo ano, o documento "Parâmetros Básicos de Infraestrutura para Instituições de Educação Infantil", que apresentou estudos e parâmetros nacionais relacionados à qualidade dos ambientes das Instituições de Educação Infantil.

Paralelamente, no âmbito da Saúde surgiram as primeiras referências legais sobre creches, no Código Sanitário do Estado de São Paulo (Decreto n. 12.342 , de 27 de setembro de 1978, artigos 114 e 196) que chegou a descrever alguns ambientes de um estabelecimento desse tipo, ainda que sem muitos detalhes ${ }^{(6)}$.

As regulamentações mais específicas da área da saúde vieram com a Portaria MS n. 321, de 26 de maio de 1988, aprovando normas e padrões mínimos para construção, instalação e o funcionamento de creches em todo o território nacional(7) e com a Resolução SS n. 44, de 30 de janeiro de 1992 - Norma Técnica para creches e estabelecimentos congêneres ${ }^{(8)}$.

No âmbito da vigilância do Estado de São Paulo, as creches foram incluídas pela Portaria CVS n. 16, de 24 de outubro de $2003^{(9)}$, com nível de

(4) BRASIL. Lei n. 9.394, de 20 de dezembro de 1996. Estabelece as diretrizes e bases da educação nacional. Diário Oficial da União, Brasília, DF, 23 dez. 1996. p. 27833-41. p. 27833-41

(5) BRASIL. Lei n. 10.172, de 9 de Janeiro de 2001. Aprova o Plano Nacional de Educação e dá outras providências. Diário Oficial da União, BRASÍLIA, DF, 10 JAN. 2001.

(6) SÃO PAULO (Estado). Decreto n. 12.342 de 27 de setembro de 1978. Aprova o Regulamento a que se refere o artigo 22 do Decreto-Lei n. 211, de 30 de março de 1970, que dispõe sobre normas de promoção, preservação e recuperação da saúde no campo de competência da Secretaria de Estado da Saúde. Diário Oficial do Estado de São Paulo, São Paulo, 1978.

(7) MINISTÉRIO DA SAÚDE. Portaria n. 321, de 26 de maio de 1988. Aprova as normas e os padrões mínimos, que com esta baixam, destinados a disciplinar a construção, instalação e funcionamento de creches, em todo o território nacional. Diário Oficial da União, Brasília, DF, 09 set. 1988.

(8) SECRETARIA DE ESTADO DA SAÚDE DE SÃO PAULO. Resolução SS n. 44, de 30 de janeiro de 1992. Aprovar a Norma Técnica para Creches e Estabelecimentos Congêneres. Diário Oficial do Estado de São Paulo, 31 de janeiro de 1992.

(9) SECRETARIA DE ESTADO DA SAÚDE DE SÃO PAULO. Centro de Vigilância Sanitária. Portaria CVS n. 16, de 24 de outubro de 2003. Dispõe sobre o Sistema Estadual de Vigilância Sanitária (SEVISA), define o Cadastro Estadual de Vigilância Sanitária (CEVS) e os procedimentos administrativos a serem adotados pelas equipes estaduais e municipais de vigilância sanitária no estado de São Paulo e dá outras providências. Diário Oficial do Estado de São Paulo, Poder Executivo, Seção I, 07 dez. 2003. 
complexidade básica, sujeitas apenas a cadastro. Mais tarde, na Portaria CVS n. 01, de 22 de janeiro de $2007^{(10)}$, passaram para nível de complexidade média, com exigência de laudo técnico de avaliação e licença de funcionamento, sob código da Classificação Nacional de Atividades Econômicas (CNAE) n. 8511-2/00.

Nessa portaria, as creches figuravam no Grupo II - Atividades de prestação de serviços de saúde/Equipamentos de Saúde, no seu item 23 - Prestação de Serviços de Saúde. Segundo a descrição dessa CNAE, as creches compreendiam "As atividades de instituições de ensino que se destinam ao desenvolvimento integral da criança, em geral, de até 6 anos de idade", de acordo com a Lei n. 9.394, de 20 de dezembro de 1996 (LDB) e "Instituições assistenciais que abrigam crianças normais ou com deficiências mentais/físicas, cujas mães são necessitadas ou trabalham fora do lar."

Desta forma, as creches encontram-se, hoje, entre os estabelecimentos obrigados a solicitar a Licença de Funcionamento, assim definida pela Portaria CVS 01/07: "ato privativo do órgão de saúde competente que permite o funcionamento dos estabelecimentos que desenvolvem atividades de acordo com a legislação sanitária vigente"(11).

Para a concessão da licença sanitária há uma série de exigências documentais, além da avaliação físico-funcional feita através da inspeção sanitária, a qual é definida na portaria supracitada como:

todo procedimento realizado pela autoridade de vigilância sanitária competente que busca levantar e avaliar "in loco" os riscos à saúde da população presentes na produção e circulação de mercadorias, na prestação de serviços e na intervenção sobre o meio ambiente, inclusive o de trabalho.

A inspeção sanitária é uma das principais tecnologias utilizadas nas ações de vigilância sanitária, porém muito pouco estudada e sistematizada nos seus elementos constituintes. Segundo Costa inspeção sanitária é definida como:

... uma prática de observação sistemática, orientada por conhecimento técnico-científico, destinada a examinar as condições sanitárias de estabelecimentos, processos, produtos, meios de transporte e ambientes e

(10) SECRETARIA DE ESTADO DA SAÚDE DE SÃO PAULO. Centro de Vigilância Sanitária. Portaria CVS n. 01, de 22 de janeiro de 2007. Dispõe sobre o Sistema Estadual de Vigilância Sanitária (SEVISA), define o Cadastro Estadual de Vigilância Sanitária (CEVS) e os procedimentos administrativos a serem adotados pelas equipes estaduais e municipais de vigilância sanitária no estado de São Paulo e dá outras providências. Diário Oficial do Estado, n. 117, 27 jan. 2007, Seção I. (Republicada em 24.03.2007 - Retificada em 29.03.2007, 04.08.2007, 21.12.2007 e 11.01.2008) (11) Id. Ibid. 
sua conformidade com padrões e requisitos de saúde pública (o destaque é nosso) que visam a proteger a saúde individual e coletiva ${ }^{(12)}$.

De acordo com sua origem, as inspeções sanitárias podem ser programadas, quando são realizadas de forma periódica e rotineira, com vistas à fiscalização e controle para concessão ou renovação da licença de funcionamento; por causa da denúncia, quando realizadas para verificar a veracidade do fato que será ou não caracterizado como infração sanitária na forma da lei; em virtude da ordem judicial, quando destinadas a cumprir determinação de autoridade competente.

Como ferramenta essencial na realização dessas inspeções, no Estado de São Paulo, a Portaria CVS n. 01/07, no artigo 26, § 3o determina que:

Institui-se a utilização dos "Roteiros de Inspeção Sanitária", instrumentos técnicos publicados pelos órgãos de vigilância sanitária das esferas federal, estadual e municipal para orientar a ação de fiscalização, na estruturação do texto que relata a situação encontrada na realização do aludido procedimento ${ }^{(13)}$.

Em contraste ao observado no Serviço de Epidemiologia e Controle de Doenças, o qual conta com muitos instrumentos e farto material de apoio, como os Manuais Técnicos e as Fichas de Investigação para cada agravo de notificação compulsória, além dos relatórios e planilhas de acompanhamento de diversos programas, nos serviços de Vigilância Sanitária nota-se marcante escassez de instrumental técnico disponível para as atividades de inspeção sanitária.

$\mathrm{Na}$ área de vigilância sanitária, o primeiro instrumento dessa natureza instituído foi o Roteiro de Inspeção em Indústria Farmacêutica, mediante a Portaria SVS/MS n. 16, de 6 de março de $1995^{(14)}$, seguido de vários outros elaborados e publicados pela Agência Nacional de Vigilância Sanitária (ANVISA) e pelo Centro de Vigilância Sanitária do Estado de São Paulo (CVS). Entretanto, ainda não está disponibilizado pelos órgãos oficiais um roteiro específico para creches e os que são encontrados em pesquisas na internet por meio da página de busca Google ${ }^{(15)}$, constituem-se de iniciativas de alguns serviços, que atendem à legislação própria do seu município ou não citam as bases legais onde se apoiam.

(12) COSTA, E. A. Vigilância sanitária: proteção e defesa da saúde. In: ROUQUAYROL, M. Z.; ALMEIDA FILHO, N. Epidemiologia e saúde. 6. ed. São Paulo: Medsi, 2003. p. 357-387.

(13) SECRETARIA DE ESTADO DA SAÚDE DE SÃO PAULO. Centro de Vigilância Sanitária. Portaria CVS n. 01, de 22 de janeiro de 2007, cit.

(14) MINISTÉRIO DA SAÚDE. Secretaria de Vigilância à Saúde. Portaria n. 16, de 6 de março de 1995. Determina a todos os estabelecimentos produtores de medicamentos, o cumprimento das diretrizes estabelecidas pelo "Guia de Boas Práticas de Fabricação para Indústrias Farmacêuticas" aprovadas na 28a Assembleia Mundial de Saúde em maio de 1975. Diário Oficial da União, Brasília, DF, 09 mar. 1995. (15) GOOGLE. Developed by Google Inc. Disponível em: <http://www.google.com.br/>. Acesso em: 10 jul. 2007. 
As instituições de educação infantil, incluindo-se as creches, tornaram-se uma necessidade e uma realidade no Brasil, assumindo um papel fundamental nas condições de vida e consequentemente na saúde das crianças que as frequentam. Dados do Instituto Nacional de Estudos e Pesquisas Educacionais Anísio Teixeira - INEP(16) informam que, em 2007, havia 1.240.209 crianças matriculadas em creches e pré-escolas no Estado de São Paulo, sendo 8.745 destas apenas no município de Diadema.

O presente estudo teve como objetivo colaborar na organização do processo de trabalho da equipe de Vigilância Sanitária do município de Diadema, preenchendo uma lacuna de instrumental técnico identificada naquele serviço; identificar os fundamentos jurídicos, técnico-científicos e sanitários que possam nortear a prática de inspeções sanitárias em creches; elaborar uma proposta de roteiro que permita um processo de análise mais explícito, objetivo e homogêneo e discutir a contribuição do instrumento proposto para a atividade de vigilância sanitária, com base na literatura científica pesquisada.

\section{METODOLOGIA}

Para a elaboração deste trabalho foi realizada uma revisão com base em textos didáticos e normativos das áreas de educação e saúde, documentos jurídicos incluindo legislações básicas de Vigilância Sanitária e Educação Infantil, roteiros já existentes de inspeção sanitária para outros estabelecimentos de interesse à saúde e artigos da literatura científica sobre agravos à saúde em crianças que frequentam creches.

Inicialmente foram consultadas as Portarias MS n. 321/88(17) e MS n. 1010/06 (18), referentes a creches, sendo a seguir realizada busca na internet, por intermédio da Biblioteca Virtual em Saúde (BVS) ${ }^{(19)}$ e do Sistema de Legislação em Vigilância Sanitária (Visalegis-ANVISA) ${ }^{(20)}$, de todos os instrumentos legais citados nessas duas portarias como "atos relacionados" e/ou no corpo das "considerações iniciais". Complementarmente, foi feita pesquisa via página de buscas

(16) INEP - Instituto Nacional de Estudos e Pesquisas Educacionais Anísio Teixeira. Censo Escolar de 2007 - resultados finais. Brasília, DF. Disponível em: <http://www.inep.gov.br/imprensa/ noticias/censo/escolar/news08_01.htm>. Acesso em: 15 fev. 2008.

(17) MINISTÉRIO DA SAÚDE. Portaria n. 321, de 26 de maio de 1988, cit.

(18) MINISTÉRIO DA SAÚDE, Ministério da Educação. Portaria Interministerial n. 1.010, de 8 de maio de 2006. Institui as diretrizes para a promoção da alimentação saudável nas escolas de educação infantil, fundamental e nível médio das redes públicas e privadas, em âmbito nacional. Diário Oficial da União, Brasília, DF, 09 maio 2006.

(19) BVS. Biblioteca Virtual em Saúde. Desenvolvido por Ministério da Saúde, BIREME/OPAS/OMS. Disponível em: <http://regional.bvsalud.org/php/index.php?lang=pt>. Acesso em: 18 jun. 2007.

(20) VISALEGIS. Desenvolvido por ANVISA e BIREME. Disponível em: <http://www.anvisa.gov.br/ e-legis/>. Acesso em: 18 jun. 2007. 
Google por meio das seguintes entradas de campo: "legislação sanitária creches", "vigilância sanitária creches" e "leis e creches".

Em seguida, foram pesquisados todos os Roteiros de Inspeção para outros serviços de interesse à saúde que haviam sido publicados pelos órgãos oficiais, pelo site da ANVISA(21) (Tecnologia da Organização dos Serviços de Saúde) e do CVS (Publicações - Roteiros e guias de Inspeção em Vigilância Sanitária)(22) não sendo encontrado nenhum para creche. Para confirmação de que não havia, realmente, nenhum roteiro de inspeção para creches publicado, foi feita uma pesquisa na rede internet por intermédio da página de buscas Google com resultado igual a dois roteiros: um do Município de Porto Alegre (RS) ${ }^{(23)}$ e outro do Município de Atibaia (SP) ${ }^{(24)}$, nenhum deles com publicação por meio de órgão oficial do Sistema Nacional de Vigilância Sanitária.

Como material de apoio para possíveis exigências a serem incluídas no roteiro e que não estivessem explicitadas na legislação reunida, foi feito um levantamento da literatura científica existente sobre agravos à saúde das crianças que frequentam creches, mediante o Sistema Integrado de Bibliotecas da Universidade de São Paulo (SIBiNet) ${ }^{(25)}$, da Biblioteca Centro de Referência em Saúde Pública/CIR ${ }^{(26)}$, da Biblioteca Digital de Teses e Dissertações ${ }^{(27)}$, da The Scientific Electronic Library Online - SciELO Brasil(28) e PubMed - serviço da U. S. National Library of Medicine ${ }^{(29)}$. As palavras-chave utilizadas no nosso idioma foram: "doenças em creches", "crianças na creche", infecções em creches", "frequência de agravos em creches" e "surtos em creches" e no idioma Inglês foram: "child day care centers", "child care", "injuries in child care centers" e "children".

(21) ANVISA. Desenvolvido pela Agência Nacional de Vigilância Sanitária, Ministério da Saúde. Disponível em: <http://www.anvisa.gov.br/servicosaude/organiza/roteiro_insp.htm>. Acesso em: 30 jun. 2007.

(22) CVS. Desenvolvido pelo Centro de Vigilância Sanitária do Estado de São Paulo. Disponível em: http://www.cvs.saude.sp.gov.br/busca_publ.asp?pg=2. Acesso em: 30 jun. 2007.

(23) PREFEITURA MUNICIPAL DE PORTO ALEGRE. Desenvolvido por PROCEMPA. Disponível em: <http://lproweb.procempa.com.br/pmpa/prefpoa/sms/usu_doc/creche_inspecao.pdf>. Acesso em: 10 jul. 2007.

(24) PREFEITURA DA ESTÂNCIA DE ATIBAIA. Desenvolvido por pela Prefeitura da Estância de Atibaia. Disponível em: <http://www.atibaia.sp.gov.br/vigilanciasanitaria/Roteiros\%20de\%20lnspe\%C3\%A7\%C3\% A3o/indexroteiros.html>. Acesso em: 10 jul. 2007.

(25) SIBiNET. Desenvolvido pelo Departamento Técnico do Serviço Integrado de Bibliotecas, Universidade de São Paulo. Disponível em: <http://www.usp.br/sibi/>. Acesso em: 17 dez. 2007.

(26) BIBLIOTECA. CENTRO DE INFORMAÇÃO E REFERÊNCIA EM SAÚDE PÚBLICA. Desenvolvido pela Faculdade de Saúde Pública da Universidade de São Paulo. Disponível em: <http:// www.bibcir.fsp.usp.br/>. Acesso em: 17 dez. 2007.

(27) BIBLIOTECA DIGITAL, TESES E DISSERTAÇÕES. Desenvolvido pela Universidade de São Paulo Disponível em: <http://www.teses.usp.br/>. Acesso em: 17 dez. 2007.

(28) SCIELO - Scientific Electronic Library Online. Desenvolvido por FAPESP/BIREME. Disponível em: <http://www.scielo.br/?lng=en>. Acesso em: 17 dez. 2007.

(29) PUBMED. Desenvilvido pelo U.S. National Library of Medicine and National Institute of Health. Disponível em: <http://www.ncbi.nlm.nih.gov/sites/entrez/>. Acesso em: 17 dez. 2007. 
Para embasamento teórico de todo o trabalho foi feita ainda uma pesquisa bibliográfica sob os temas: "Práticas de Vigilância Sanitária" e "Inspeção Sanitária" e em livros de interesse para o tema.

A leitura do material acompanhou o processo de pesquisa, iniciando pelos livros selecionados, com ênfase nos capítulos pertinentes ao tema do trabaIho, seguida pelos textos de apoio, para resgate histórico do papel das creches no cenário brasileiro e sua interface com a saúde da população infantil.

Posteriormente, foram avaliados os trabalhos científicos levantados, buscando identificar possíveis achados conclusivos de nexo causal entre frequência de crianças às creches e a incidência de agravos à saúde das mesmas. Para cada trabalho foram feitos apontamentos sobre os resultados, conclusões e recomendações, assinalando sua relação com o tema abordado.

A seguir, com base nas legislações pertinentes, foi elaborada uma proposta inicial de roteiro para inspeção sanitária em creches, submetendo o material à diagramação do texto e a uma primeira revisão. A seguir, foram introduzidos tópicos adicionais ao roteiro conforme necessidades identificadas através mediante os apontamentos dos trabalhos científicos lidos, finalizando a sua elaboração após a última revisão.

\section{RESULTADOS E DISCUSSÃO}

O roteiro apresentado (QUADRO 1) foi elaborado com o propósito de ser aplicado de forma autoexplicativa quanto a eventuais classificações solicitadas e traz as referências legais associadas aos itens a serem observados, objetivando facilitar a identificação das mesmas na elaboração de documentos decorrentes da inspeção.

É composto de um formulário inicial com dados da caracterização do estabelecimento seguido por uma série de formulários, contemplando a estrutura interna, externa e da construção. Foram abordados também dados sobre recursos humanos disponíveis e da documentação exigida.

De acordo com Alves:

Há que se ressaltar que os instrumentos de controle sanitário tendem a ter um nível de abrangência cada vez maior, frente ao avanço tecnológico e à globalização dos mercados, que possibilita uma circulação de bens e serviços envolvendo níveis de risco diferenciados que exigem melhores condições para a realização da inspeção sanitária, possibilitando assim que seja atingida a sua finalidade ${ }^{(30)}$.

(30) ALVES, M. G. H.; ALBUQUERQUE, M. G.; FERNANDES, R. M. B. S. Vigilância sanitária: a inspeção sanitária - uma tecnologia a serviço da saúde. Coletânea de monografias do curso de especialização em saúde coletiva com concentração em vigilância sanitária. Organizadora Maria das Graças Hortélio Alves. - Salvador-Ba: DIVISA; ISC, 2004. p. 152. 
Este trabalho focalizou o conteúdo da legislação específica vigente e sua aplicabilidade na prática da inspeção sanitária em creches e, nesse sentido, a Portaria n. 321/88 ${ }^{(31)}$ do Ministério da Saúde é, sem dúvida, a que normatiza com maior abrangência e detalhamento a estrutura, a instalação e o funcionamento das creches, sendo, portanto, tomada como base para a composição da proposta de roteiro. No entanto, logo de início foi constatada uma divergência em relação à idade: enquanto a supracitada portaria delimita entre três meses a quatro anos, outras normatizações - CVS n. 01/07(32) e Resolução SS n. 44/92(33) — fixam em "até 6 anos e 11 meses" a faixa etária da população atendida nas creches.

Tendo em vista que a atuação das equipes de Vigilância Sanitária é regulamentada pela Portaria CVS n. 01/07, considerou-se no presente trabalho a faixa etária nela descrita, ou seja, de zero a seis anos de idade, definida na LDB como "Educação Infantil".

Em relação ao conteúdo, a Portaria Ministerial n. 321/88 define e especifica em detalhes os diversos ambientes (denominados elementos) que devem fazer parte das creches, de acordo com o porte da mesma. Foram considerados todos os elementos que possam, de alguma forma, interferir na saúde das crianças e excluídos do roteiro aqueles, como por exemplo, o auditório e alguns itens da unidade de administração, cuja existência ou ausência não determinam riscos sanitários. O item 12 dessa Portaria traz, para efeito de cálculo das áreas físicas destinadas ao pessoal, uma relação de profissionais que, provavelmente em razão de erros na digitação, deixa dúvidas quanto ao número previsto para cada função - exemplo - oito auxiliares de lactário para uma creche de 50 crianças. Para a elaboração das especificações do quadro mínimo de pessoal, foi utilizada a relação constante da Resolução n. 44/SES ${ }^{(34)}$, considerada mais adequada e exequível. A formação escolar mínima dos docentes seguiu a exigência estabelecida pela Lei de Diretrizes e Bases, por entender-se que a fiscalização das condições do exercício profissional desse tipo de atividade deve ser normatizada por órgãos da área de educação.

Considerando que uma das grandes responsabilidades da creche é a alimentação e que esta deve ser adequada e segura, do ponto de vista higiênico-sanitário, decidiu-se buscar legislação mais específica, uma vez que a Portaria Ministerial n. $321 / 88^{(35)}$ trata desse elemento de forma não pormenorizada. A busca por um instrumento que institui as diretrizes para a promoção da alimentação saudável nas escolas públicas e privadas do país

(31) MINISTÉRIO DA SAÚDE. Portaria n. 321, de 26 de maio de 1988, cit.

(32) SECRETARIA DE ESTADO DA SAÚDE DE SÃO PAULO. Centro de Vigilância Sanitária. Portaria CVS n. 01, de 22 de janeiro de 2007, cit.

(33) SECRETARIA DE ESTADO DA SAÚDE DE SÃO PAULO. Resolução SS n. 44, de 30 de janeiro de 1992, cit.

(34) Id. Ibid.

(35) MINISTÉRIO DA SAÚDE. Portaria n. 321, de 26 de maio de 1988, cit. 
resultou na Portaria Interministerial n. 1010/06(36) que define que as mesmas devem estar adequadas às boas práticas para serviços de alimentação, de acordo com os regulamentos vigentes. Tal determinação nos remete à Resolução de Diretoria Colegiada n. 216/04(37) que estabelece procedimentos de Boas Práticas para serviços de alimentação. Com base nessa RDC foram incluídos itens a serem observados e pesquisados durante a inspeção sanitária.

Quanto à literatura científica consultada, a maioria das recomendações relacionadas com a diminuição da ocorrência de agravos ratifica o que já se encontra na legislação específica em vigor e nas ações de controle de riscos sanitários, tendo sido encontrados apenas alguns pontos a serem incluídos.

Diversas pesquisas investigaram fatores ambientais como causa de agravos variados à saúde das crianças que frequentam creches. Munir $e$ col.(38), em 1996, demonstraram que formas diferentes de renovação do ar ambiental e rotinas de limpeza interferem na qualidade do ar das creches em relação aos alérgenos de pelos de cães e gatos presentes na poeira. Para minimizar esse problema, recomendam medidas como: instalação de ventilação mecânica quando indicado, limpeza constante das superfícies e afastamento das crianças do contato direto com cães e gatos nas creches.

Ainda sobre qualidade do ar, Zuraimi e col.(39) concluíram que a prevalência de casos de rinite alérgica, asma e sintomas respiratórios é maior nas creches que usam exclusivamente sistema de ar condicionado, ou mesmo intercalado com ventilação mecânica ou natural, do que as creches que possuem apenas ventilação natural.

Ljunberg e col.(40) estudaram a incidência de traumas não intencionais em mãos e antebraços de crianças de zero a seis anos, evidenciando que $83 \%$ deles aconteceram na presença de adultos e $49 \%$ enquanto as crianças brincavam. Em $29 \%$ dos casos, o ferimento foi causado por mão presa em porta fechada por outra criança, com taxa de hospitalização de $65 \%$. Os autores listam dez sugestões para evitar traumatismos de mão nessa faixa

(36) MINISTÉRIO DA SAÚDE, Ministério da Educação. Portaria Interministerial n. 1.010, de 8 de maio de 2006, cit.

(37) AGÊNCIA NACIONAL DE VIGILÂNCIA SANITÁRIA. Resolução-RDC n. 216, de 15 de setembro de 2004. Dispões sobre Regulamento Técnico de Boas Práticas para Serviços de Alimentação. DOU - Diário Oficial da União. Poder Executivo, Brasília, 16 set. 2004.

(38) MUNIR A. K.; EINARSSON, R,, DREBORG, S. Allergen avoidance in a day-care center. Allergy, v. 51, n.1, p. 36-41, Jan 1996.

(39) ZURAIMI, M. S.; THAM, K. W.; CHEW, F. T.; OOI, P. L. The effect of ventilation strategies of child care centers on indoor air quality and respiratory health of children in Singapore. Indoor Air, v. 17, n. 4, p. 317-327, 2007.

(40) LJUNGBERG, E. M.; CARISSON, K. S.; DAHLIN, L. B. Risks of, and causes of, injuries to the hand and forearm: a study in children 0 to 6 years old. Scandinavian Journal of Plastic and Reconstructive Surgery and Hand Surgery, Scandinavia, v. 40, n. 3, p. 166-174, 2006. 
etária, entre os quais a instalação de dispositivos de segurança como dobradiças inteiriças nas portas que impedem a formação de vãos enquanto abertas e membranas de borracha entre a porta e o batente.

Em relação ao playground, Kotch e col.(41) demonstraram que o estabelecimento de normas de segurança para uso do playground reduziu em $22 \%$, no período de três anos, os casos de acidentes em crianças de creche que necessitaram de atendimento médico nos Estados Unidos.

Ainda sobre a questão de regulamentação nas creches, outro estudo, de Currie e Hotz $^{(42)}$, avaliou o impacto do estabelecimento de regras para provedores de cuidados a crianças, imposto pelo governo dos Estados Unidos entre os anos 80 e 90 . Os autores constataram que houve uma diminuição significativa do risco de danos fatais e não fatais com o aumento de escolaridade dos profissionais, incluindo o diretor da creche. A proporção criança/cuidador também foi apontada como fator determinante do número de acidentes ocorridos.

Conclusões semelhantes foram apontadas no trabalho de Waibel e Misra $^{(43)}$ que estudaram a ocorrência de ferimentos em crianças de zero a 12 anos em 2000, nos Estados Unidos, onde a maioria ocorreu em crianças que estavam inseridas em programas de cuidados. As crianças que começaram a andar recentemente estavam mais sujeitas a quedas e mordeduras, com $50 \%$ dos casos evoluindo para infecção. Os autores apontaram que os cuidadores precisam estar treinados para agir rápida e corretamente, pois, os primeiros cuidados são fundamentais para prevenir infecções secundárias.

Outro estudo ${ }^{(44)}$ apontou a necessidade de formação e educação continuada dos profissionais das creches relativos à prevenção, detecção precoce e manejo das infecções respiratórias agudas na infância, pela alta frequência com que ocorrem nas crianças desses locais.

Já Fuchs e col.(45) associaram a frequência à creche com maior número de infecção respiratória e hospitalização, que aumenta proporcionalmente ao número de horas que a criança permanece nesse ambiente. Demonstraram que a permanência das crianças por 12 a 50 horas semanais nas cre-

(41) KOTCH, J. B.; HUSSEY, J. M.; CARTER, A. Evaluation of North Carolina child care safety regulations. Injury Prevention, v. 9, n. 3, p. 220-225, Sept. 2003.

(42) CURRIE, J.; HOTZ, V. J. Accidents will happen? Unintentional childhood injuries and the effects of child care regulations. Journal of Health Economics, v. 23, n. 1, p. 25-59, Jan. 2004.

(43) WAIBEL, R.; MISRA, R. Injuries to preschool children and infection control practices in childcare programs. Journal of School Health, v. 73, n. 5, p. 167-172, 2003.

(44) MARTINS J.; VERÍSSIMO, M. L. Ó. R. Conhecimentos e práticas de trabalhadoras de creches municipais relativos ao cuidado da criança com infecção respiratória aguda. Interface, Botucatu, v. 10, n. 20, p. 487-504, jul./dez. 2006.

(45) FUCHS, S. C.; MAYNART, R. C.; COSTA, L. F. DA. Tempo de permanência na creche e infecção respiratória aguda. Cadernos de Saúde Pública, v. 12, n. 3, p. 291-296, 1996. 
ches determina um risco aproximadamente três a cinco vezes maior de ter uma infecção respiratória aguda. Tal conclusão corrobora as recomendações apontadas por estudo de Martins e Veríssimo.

Outro autor fez uma revisão de estudos sobre associação entre ocorrência de infecções respiratórias e diarreia em crianças expostas a creches e, apesar de diferenças metodológicas e variação na magnitude encontrada, avaliou tal associação como consistente ${ }^{(46)}$.

Finalmente, foram analisados alguns estudos sobre a contaminação nos ambientes das creches, justificando várias exigências apontadas na legislação sanitária referente a esses estabelecimentos.

Em 2004, Boone e Gerba(47) investigaram e demonstraram a ocorrência sazonal de vírus influenza A, nas superfícies de fômites em creches, com aumento durante a primavera. Concluíram que o baixo índice da ocorrência desse vírus nos brinquedos e no chão poderia estar relacionado à maior frequência nos procedimentos de limpeza.

Num estudo feito por Laborde e col.(48), foi demonstrado risco aumentado de ocorrência de diarreia associado à contaminação fecal nas mãos de crianças e funcionários, nas torneiras e superfícies de lavatórios (nível alto de contaminação) com recomendação das seguintes medidas para minimizar esse risco: 1) designação de um único funcionário por classe para a troca de fraldas; 2) instalação de torneiras acionadas sem uso das mãos; e 3) sanitização de fômites, torneiras e brinquedos após cada uso.

Van e col.(49) já haviam apontado que os locais mais contaminados por coliformes fecais, nas creches, são a área de troca de fraldas, a alça do recipiente de descarte de fraldas acionada manualmente, o chão da área de brincar, os assentos das cadeiras e cadeirões e os brinquedos de plástico. Evidenciou também que a contaminação das mãos das crianças e cuidadoras é muito comum e que usar roupas por cima das fraldas diminui essa contaminação. Outras recomendações incluem lavagem das mãos a cada troca de fraldas (crianças e cuidadoras), limpeza frequente da área de troca de fraldas e do chão e isolamento das crianças com diarreia em relação às saudáveis.

(46) BARROS, A. J. D. Frequência a creches e morbidade comum na infância: evidência de associação na literatura e problemas de delineamento. Revista de Saúde Pública. São Paulo, v. 33, n. 1, p. 98106, fev. 1999.

(47) BOONE, A. S.; GERBA, C. P. The occurrence of influenza A virus on household and day care center fomites. Journal of Infection, v. 51, n. 2, p. 103-109, Aug., 2005.

(48) LABORDE, D. J.; WEIGLE, K. A.; WEBER, D. J.; KOTCH, J. B. Effect of fecal contamination on diarrheal illness rates in day-care centers. American Journal of Epidemiology, v. 138, n. 4, p. 243-255, 1993.

(49) VAN, R.; MORROW, A. L.; REVES, R. R.; PICKERING, L. K. Environmental contamination in child day-care centers. American Journal of Epidemiology, v. 133, n. 5, p. 460-470, 19911. 
Kotch e col. ${ }^{(50)}$ ratificaram esses achados mediante estudo onde demonstraram que a instalação de equipamentos com material de boa qualidade para troca de fraldas, assim como para o preparo de alimentos, apesar de onerosos, reduz significativamente a frequência de doença diarreica nas creches. Finalmente, afirmaram que qualquer intervenção para reduzir diarreia e outras doenças infecciosas nas creches, depende, em grande parte, dos conhecimentos, da perícia e da capacitação dos cuidadores.

Estudo brasileiro realizado por Menezes e col.(51) em creche pública de Fortaleza encontrou menor índice de contaminação por Candida albicans (18\%) em relação ao trabalho realizado em escolares de Piracicaba por Moreira e col. $(47,3 \%)$ e atribuiu a diferença a treinamentos constantes dos profissionais da creche onde foi realizado(52).

Mais um estudo evidenciou que em crianças maiores de dois anos, houve um impacto de $66 \%$ a menos na ocorrência de diarreia após treinamento de lavagem de mãos para crianças e cuidadoras ${ }^{(53)}$.

Por fim, trabalho de Staskel e col.(54), apontou a associação entre a higienização inadequada das superfícies dos serviços de nutrição das creches e a maior ocorrência de doenças entéricas por bacilos Gram negativos nas crianças que as frequentam e recomendaram: limpeza das superfícies com cloro, treinamento adequado de manipuladores de alimentos e maior frequência das inspeções.

Entende-se que o processo de aprendizagem e a integração com a comunidade escolar têm interface com a sanidade mental e o bem-estar da criança, uma vez considerada a concepção positiva e holística de saúde.

O cuidado como atividade permanente e essencial também está contemplado no Referencial Curricular Nacional para a Educação Infantil - RCNEI, que afirma: “(...) cuidar de uma criança em um contexto educa-

(50) KOTCH, J. B.; HUSSEY, J. M.; CARTER, op. cit.

(51) MENEZES, E. A.; CAVALCANTE, M. S.; FARIAS, R. B.; TEIXEIRA, A. B.; PINHEIRO, F. G.; BEZERRA, B. P. et al. Frequency and enzymatic activity of Candida albicans isolated from the buccal mucosa of children of a day-care center of the city hall of Fortaleza, Ceará, Brazil. Jornal Brasileiro de Patologia e Medicina Laboratorial, Rio de Janeiro, v. 41, n. 1, p. 9-13, fev. 2005.

(52) MOREIRA, D.; SPOLIDÓRIO, D. M. P.; RODRIGUES, J. A. de O.; BORIOLLO, M. F. G.; PEREIRA, C. V.; ROSA, E. A. R.; HOFLING, J. F. Candida spp. biotypes in the oral cavity of school children from different socioeconomic categories in Piracicaba - SP, Brasil. Pesquisa Odontologica Brasileira, v. 15, n. 3, p.187-195, 2001.

(53) ROBERTS, L.; SMITH, W.; JORM, L.; PATEL, M.; DOUGLAS, R. M.; MCGILCHRIST, C. Effect of infection control measures on the frequency of upper respiratory infection in child care:a randomized,controlled trial. Pediatrics, v. 105, n. 4, p. 738-742, Apr. 2000.

(54) STASKEL, D. M.; BRILEY, M.E.; FIELD, L. H.; BARTH, S. S. Microbial evaluation of foodservice surfaces in Texas child-care centers. Journal of American Diet Association, v. 107, n. 5, p. 854-859, 2007. 
tivo demanda a integração de vários campos de conhecimentos e a cooperação de profissionais de diferentes áreas."(55) Sobre as diversas metodologias utilizadas para a melhoria da qualidade dos estabelecimentos de educação infantil, Souza e Carvalho ${ }^{(56)}$ elaboraram um estudo sobre escalas de avaliação criadas por autores americanos - ECERS - e ITERS ${ }^{(57)(58)}$, para crianças até 30 meses de idade ou de quatro a seis anos, respectivamente. Concluíram informando que a escala ITERS estava sendo, à época, traduzida para a Língua Portuguesa e havia dois projetos em andamento com o objetivo de analisar princípios de qualidade em documentos nacionais e estrangeiros.

Com a reorganização do sistema educacional, por um lado - LDB, 1996 - e a implantação do Sistema Único de Saúde ${ }^{(59)}$ por outro - Lei n. 8.080 , de 19 de setembro de $1990^{(60)}$ - a responsabilidade pela manutenção das creches e pré-escolas passou a ser dos municípios, representando uma demanda constante em nível local e tornando-se objeto propício para a implementação de ações de saúde e educativas. Nesse sentido, a inserção das creches nas áreas de abrangência do Programa de Saúde da Família (PSF) pode favorecer uma integração de ações de educação em saúde e, principalmente, as ações de Vigilância à Saúde.

\section{CONSIDERAÇÕES FINAIS}

As creches estão enquadradas entre os estabelecimentos de interesse à saúde por serem espaços destinados aos cuidados de crianças durante seis a 12 horas diárias o que justifica, por si só, a necessidade de uma prática de atendimento cujo princípio seja garantir as melhores oportunidades de desenvolvimento a essas crianças.

Todas essas considerações levam à conclusão de que um modelo eficiente de controle e supervisão da qualidade dos cuidados prestados nas creches teria que ser intersetorialmente articulado, envolvendo saberes e

(55) MINISTÉRIO DA EDUCAÇÃO E DO DESPORTO. Secretaria de Educação Fundamental. Referencial curricular nacional para a educação infantil. Brasília, DF; 1998.v. 1.

(56) SOUZA, T. N. de; CAMPOS-DE-CARVALHO, M. I. Qualidade de ambientes de creches: uma escala de avaliação. Psicologia em Estudo, Maringá, v. 10, n. 1, p. 87-96, jan./abr. 2005.

(57) HARMS, T.; CLIFFORD, R. M. Early childhood environment rating scale. New York: Teachers College Press, 1980. p. 40.

(58) HARMS, T.; CRYER, D.R.; CLIFFORD, R. M. Infant/Toddler environment rating scale. New York: Teachers College Press, 1990. Disponível em: <http://pediatrics.aappublications.org/cgi/content/ full/120/1/e29>.

(59) BRASIL. Lei n. 9.394, de 20 de dezembro de 1996, cit.

(60) MINISTÉRIO DA SAÚDE. Lei n. 8.080/90. Lei Orgânica da Saúde - 1990. Manual de Gestor SUS. Lidador, Rio de Janeiro, 1997. 
olhares dos profissionais das áreas de educação e saúde. Conforme observado no presente estudo, não faltam bases legais, tanto na área de educação como na de saúde, para que os órgãos públicos assumam efetivamente a fiscalização dos estabelecimentos de Educação Infantil, inclusive com intervenções educativas e de orientação técnica, sempre com enfoque no controle dos riscos à saúde e na qualidade do atendimento prestado.

A análise do conteúdo desenvolvido no presente trabalho revelou a pertinência do mesmo em avaliar a qualidade do atendimento nas creches, no que se refere à minimização ou eliminação dos riscos à saúde das crianças e a necessidade de estudos posteriores a fim de validá-lo para o nosso contexto.

Uma próxima etapa de trabalho seria a aplicação do roteiro de inspeção em estudo de amostragem com vistas a sua adequação nos pontos onde couber e posteriormente a elaboração de um sistema de classificação e de critérios de avaliação, possivelmente estabelecido mediante uma metodologia estatística para os padrões de conformidade.

\section{REFERÊNCIAS BIBLIOGRÁFICAS}

AGÊNCIA NACIONAL DE VIGILÂNCIA SANITÁRIA. Resolução RDC n. 216, de 15 de setembro de 2004. Dispões sobre Regulamento Técnico de Boas Práticas para Serviços de Alimentação. DOU - Diário Oficial da União. Poder Executivo, Brasília, 16 set. 2004.

ALVES, M. G. H.; ALBUQUERQUE, M. G.; FERNANDES, R. M. B. S. Vigilância sanitária: a inspeção sanitária - uma tecnologia a serviço da saúde. Coletânea de monografias do curso de especialização em saúde coletiva com concentração em vigilância sanitária. Organizadora Maria das Graças Hortélio Alves. - Salvador-Ba: DIVISA; ISC, 2004.

ALVES, R. C. P. Percepções de educadoras e proposta institucional acerca dos cuidados infantis de saúde em creche. 2006. 93 p. Dissertação (Mestrado). Escola de Enfermagem da Universidade de São Paulo, São Paulo, 2006.

ANVISA. Desenvolvido pela Agência Nacional de Vigilância Sanitária, Ministério da Saúde. Disponível em: <http://www.anvisa.gov.br/servicosaude/ organiza/roteiro_insp.htm>. Acesso em: 30 jun. 2007.

BARROS, A. J. D. Frequência a creches e morbidade comum na infância: evidência de associação na literatura e problemas de delineamento. Revista de Saúde Pública. São Paulo, v. 33, n. 1, p. 98-106, fev. 1999.

BIBLIOTECA. CENTRO DE INFORMAÇÃO E REFERÊNCIA EM SAÚDE PÚBLICA. Desenvolvido pela Faculdade de Saúde Pública da Universidade de São Paulo. Disponível em: <http://www.bibcir.fsp.usp.br/>. Acesso em: 17 dez. 2007. 
BIBLIOTECA DIGITAL, TESES E DISSERTAÇÕES. Desenvolvido pela Universidade de São Paulo Disponível em: <http://www.teses.usp.br/>. Acesso em: 17 dez. 2007.

BOONE, A.S.; GERBA, C.P. The occurrence of influenza A virus on household and day care center fomites. Journal of Infection, v. 51, n. 2, p. 103-109, Aug., 2005.

BRASIL. Constituição (1988). Constituição da República Federativa do Brasil. Brasília, DF: Senado; 1988.

BRASIL. Lei n. 8.069, de 13 de Julho de 1990. Dispõe sobre o Estatuto da Criança e do Adolescente, e dá outras providências. Diário Oficial da União, Brasília, DF, 16 jul. 1990.

BRASIL. Lei n. 9.394, de 20 de dezembro de 1996. Estabelece as diretrizes e bases da educação nacional. Diário Oficial da União, Brasília, DF, 23 dez. 1996.

BRASIL. Lei n. 10.172, de 9 de janeiro de 2001. Aprova o Plano Nacional de Educação e dá outras providências. Diário Oficial da União, Brasília, DF, 10 jan. 2001.

BVS. Biblioteca Virtual em Saúde. Desenvolvido por Ministério da Saúde, BIREME/OPAS/OMS. Disponível em: <http://regional.bvsalud.org/php/index.php? lang=pt>. Acesso em: 18 JUN. 2007.

COSTA, E. A. Vigilância sanitária: proteção e defesa da saúde. In: ROUQUAYROL, M. Z.; ALMEIDA FILHO, N. Epidemiologia e saúde. 6. ed. São Paulo: Medsi, 2003. p. 357-387.

CURRIE, J.; HOTZ, V. J. Accidents will happen? Unintentional childhood injuries and the effects of child care regulations. Journal of Health Economics, v. 23, n. 1, p. 25-59, Jan. 2004.

CVS. Desenvolvido pelo Centro de Vigilância Sanitária do Estado de São Paulo. Disponível em: <http://www.cvs.saude.sp.gov.br/busca_publ.asp?pg=2>. Acesso em: 30 jun. 2007.

FUCHS, S.C.; MAYNART, R. C.; COSTA, L. F. DA. Tempo de permanência na creche e infecção respiratória aguda. Cadernos de Saúde Pública, v. 12, n. 3, p. 291-296, 1996.

GOOGLE. Developed by Google Inc. Disponível em: <http://www.google.com.br/ >. Acesso em: 10 jul. 2007.

HARMS, T.; CLIFFORD, R. M. Early childhood environment rating scale. New York: Teachers College Press, 1980.

HARMS, T.; CRYER, D. R.; CLIFFORD, R. M. Infant/Toddler environment rating scale. New York: Teachers College Press, 1990. Disponível em: <http:// pediatrics.aappublications.org/cgi/content/full/120/1/e29>. 
INEP - Instituto Nacional de Estudos e Pesquisas Educacionais Anísio Teixeira. Censo Escolar de 2007 - resultados finais. Brasília, DF. Disponível em: <http://www.inep.gov.br/imprensa/noticias/censo/escolar/news08_01.htm>. Acesso em: 15 fev. 2008.

KOTCH, J. B.; HUSSEY, J. M.; CARTER, A. Evaluation of North Carolina child care safety regulations. Injury Prevention, v. 9, n. 3, p. 220-225, Sept. 2003.

LABORDE, D. J.; WEIGLE, K. A.; WEBER, D. J.; KOTCH, J. B. Effect of fecal contamination on diarrheal illness rates in day-care centers. American Journal of Epidemiology, v. 138, n. 4, p. 243-255, 1993.

LJUNGBERG, E. M.; CARISSON, K. S.; DAHLIN, L. B. Risks of, and causes of, injuries to the hand and forearm: a study in children 0 to 6 years old. Scandinavian Journal of Plastic and Reconstructive Surgery and Hand Surgery, Scandinavia, v. 40, n. 3, p. 166-174, 2006.

MARTINS J.; VERÍSSIMO, M. L. Ó. R. Conhecimentos e práticas de trabalhadoras de creches municipais relativos ao cuidado da criança com infecção respiratória aguda. Interface, Botucatu, v. 10, n. 20, p. 487-504, jul./dez. 2006.

MENEZES, E. A.; CAVALCANTE, M. S.; FARIAS, R. B.; TEIXEIRA, A. B.; PINHEIRO, F. G.; BEZERRA, B. P. et al. Frequency and enzymatic activity of Candida albicans isolated from the buccal mucosa of children of a day-care center of the city hall of Fortaleza, Ceará, Brazil. Jornal Brasileiro de Patologia e Medicina Laboratorial, Rio de Janeiro, v. 41, n. 1, p. 9-13, fev. 2005.

MINISTÉRIO DA EDUCAÇÃO. Secretaria de Educação Básica. Política Nacional de Educação Infantil: pelo direito das crianças de zero a seis anos à educação. Brasília: MEC, SEB, 2006. 32 p.

MINISTÉRIO DA EDUCAÇÃO E DO DESPORTO. Secretaria de Educação Fundamental. Referencial curricular nacional para a educação infantil. Brasília, DF, 1998.v. 1.

MINISTÉRIO DA SAÚDE. Lei n. 8.080/90. Lei Orgânica da Saúde - 1990. Manual de Gestor SUS. Lidador, Rio de Janeiro, 1997.

MINISTÉRIO DA SAÚDE, Ministério da Educação. Portaria Interministerial $\mathrm{n}$. 1.010, de 8 de maio de 2006. Institui as diretrizes para a Promoção da Alimentação saudável nas Escolas de educação infantil, fundamental e nível médio das redes públicas e privadas, em âmbito nacional. Diário Oficial da União, Brasília, DF, 09 maio 2006.

Portaria n. 321, de 26 de maio de 1988. Aprova as normas e os padrões mínimos, que com esta baixam, destinados a disciplinar a construção, instalação e funcionamento de creches, em todo o território nacional. Diário Oficial da União, Brasília, DF, 09 set. 1988. 
MINISTÉRIO DA SAÚDE. Secretaria de Vigilância à Saúde. Portaria n. 16 de 6 de março de 1995. Determina a todos os estabelecimentos produtores de medicamentos, o cumprimento das diretrizes estabelecidas pelo "Guia de Boas Práticas de Fabricação para Indústrias Farmacêuticas" aprovadas na 28a Assembleia Mundial de Saúde em maio de 1975. Diário Oficial da União, Brasília, DF, 09 mar. 1995.

MOREIRA, D.; SPOLIDÓRIO, D. M. P.; RODRIGUES, J. A. de O.; BORIOLLO, M. F. G.; PEREIRA, C. V.; ROSA, E. A. R.; HOFLING, J. F. Candida spp. biotypes in the oral cavity of school children from different socioeconomic categories in Piracicaba - SP, Brasil. Pesquisa Odontologica Brasileira, v. 15, n.3, p.187-195, 2001.

MORO C. S. As concepções sobre o sistema público de educação infantil de mães que utilizam e que não utilizam creches. UFPR, 2004. Disponível em: <http://www.anped.org.br/reunioes/27/gt07/t071.pd>. Acesso em: 15 out. 2007.

MUNIR A. K.; EINARSSON, R.; DREBORG, S. Allergen avoidance in a daycare center. Allergy, v. 51, n.1, p. 36-41, Jan. 1996.

PREFEITURA DA ESTÂNCIA DE ATIBAIA. Desenvolvido por pela Prefeitura da Estância de Atibaia. Disponível em: <http://www.atibaia.sp.gov.br/vigilanciasanitaria/Roteiros\%20de\%20Inspe $\%$ C3\%A7\%C3\%A3o/indexroteiros.html>. Acesso em: 10 jul. 2007.

PREFEITURA MUNICIPAL DE PORTO ALEGRE. Desenvolvido por PROCEMPA. Disponível em: <http://lproweb.procempa.com.br/pmpa/prefpoa/sms/ usu_doc/creche_inspecao.pdf>. Acesso em: 10 jul. 2007.

PUBMED. Desenvilvido pelo U. S. National Library of Medicine and National Institute of Health. Disponível em: <http://www.ncbi.nlm.nih.gov/sites/entrez/>. Acesso em: 17 dez. 2007.

ROBERTS, L.; SMITH, W.; JORM, L.; PATEL, M.; DOUGLAS, R. M.; MCGILCHRIST, C. Effect of infection control measures on the frequency of upper respiratory infection in child care:a randomized,controlled trial. Pediatrics, v. 105, n. 4, p. 738-742, Apr. 2000.

SÃO PAULO (Estado). Decreto n. 12. 342, de 27 de setembro de 1978. Aprova o Regulamento a que se refere o artigo 22 do Decreto-Lei n. 211, de 30 de março de 1970, que dispõe sobre normas de promoção, preservação e recuperação da saúde no campo de competência da Secretaria de Estado da Saúde. Diário Oficial do Estado de São Paulo, São Paulo, 1978.

. Lei n. 10.083, de 23 de setembro de 1998. Dispõe sobre o Código Sanitário do Estado. Diário Oficial da União, Seção I, São Paulo, 24 set. 1998.

SCIELO - Scientific Electronic Library Online. Desenvolvido por FAPESP/BIREME. Disponível em: <http://www.scielo.br/?lng=en>. Acesso em: 17 dez. 2007. 
SECRETARIA DE ESTADO DA SAÚDE DE SÃO PAULO. Resolução SS n. 44, de 30 de janeiro de 1992. Aprova a Norma Técnica para Creches e Estabelecimentos Congêneres. Diário Oficial do Estado de São Paulo, 31 de janeiro de 1992.

SECRETARIA DE ESTADO DA SAÚDE DE SÃO PAULO. Centro de Vigilância Sanitária. Portaria CVS n. 16, de 24 de outubro de 2003. Dispõe sobre o Sistema Estadual de Vigilância Sanitária (SEVISA), define o Cadastro Estadual de Vigilância Sanitária (CEVS) e os procedimentos administrativos a serem adotados pelas equipes estaduais e municipais de vigilância sanitária no estado de São Paulo e dá outras providências. Diário Oficial do Estado de São Paulo, Poder Executivo, Seção I, 07 dez. 2003.

SECRETARIA DE ESTADO DA SAÚDE DE SÃO PAULO. Centro de Vigilância Sanitária. Portaria CVS n. 01, de 22 de janeiro de 2007. Dispõe sobre o Sistema Estadual de Vigilância Sanitária (SEVISA), define o Cadastro Estadual de Vigilância Sanitária (CEVS) e os procedimentos administrativos a serem adotados pelas equipes estaduais e municipais de vigilância sanitária no estado de São Paulo e dá outras providências. Diário Oficial do Estado, n. 117, 27 jan. 2007, Seção I. (Republicada em 24.03.2007 - Retificada em 29.03.2007, 04.08.2007, 21.12.2007 e 11.01.2008).

SIBI NET. Desenvolvido pelo Departamento Técnico do Serviço Integrado de Bibliotecas, Universidade de São Paulo. Disponível em: <http://www.usp.br/ sibi/>. Acesso em: 17 dez. 2007.

SOUZA, T. N. de; CAMPOS-DE-CARVALHO, M. I. Qualidade de ambientes de creches: uma escala de avaliação. Psicologia em Estudo, Maringá, v. 10, n. 1, p. 87-96, jan./abr. 2005.

STASKEL, D. M.; BRILEY, M. E.; FIELD, L. H.; BARTH, S. S. Microbial evaluation of foodservice surfaces in Texas child-care centers. Journal of American Diet Association, v. 107, n. 5, p. 854-859, 2007.

VAN, R.; MORROW, A. L.; REVES, R. R.; PICKERING, L. K. Environmental contamination in child day-care centers. American Journal of Epidemiology, v. 133 , n. 5 , p. 460-470, 1991.

VISALEGIS. Desenvolvido por ANVISA e BIREME. Disponível em: <http:// www.anvisa.gov.br/e-legis/>. Acesso em: 18 jun. 2007.

WAIBEL, R.; MISRA, R. Injuries to preschool children and infection control practices in childcare programs. Journal of School Health, v. 73, n. 5, p. 167172, 2003.

ZURAIMI, M. S.; THAM, K. W.; CHEW, F. T.; OOI, P. L. The effect of ventilation strategies of child care centers on indoor air quality and respiratory health of children in Singapore. Indoor Air, v. 17, n. 4, p. 317-327, 2007. 
QUADRO 1. PROPOSTA DE ROTEIRO DE INSPEÇÃO PARA CRECHES

\begin{tabular}{|l|l|}
\hline CADASTRAMENTO & FOLHA INICIAL \\
\hline
\end{tabular}

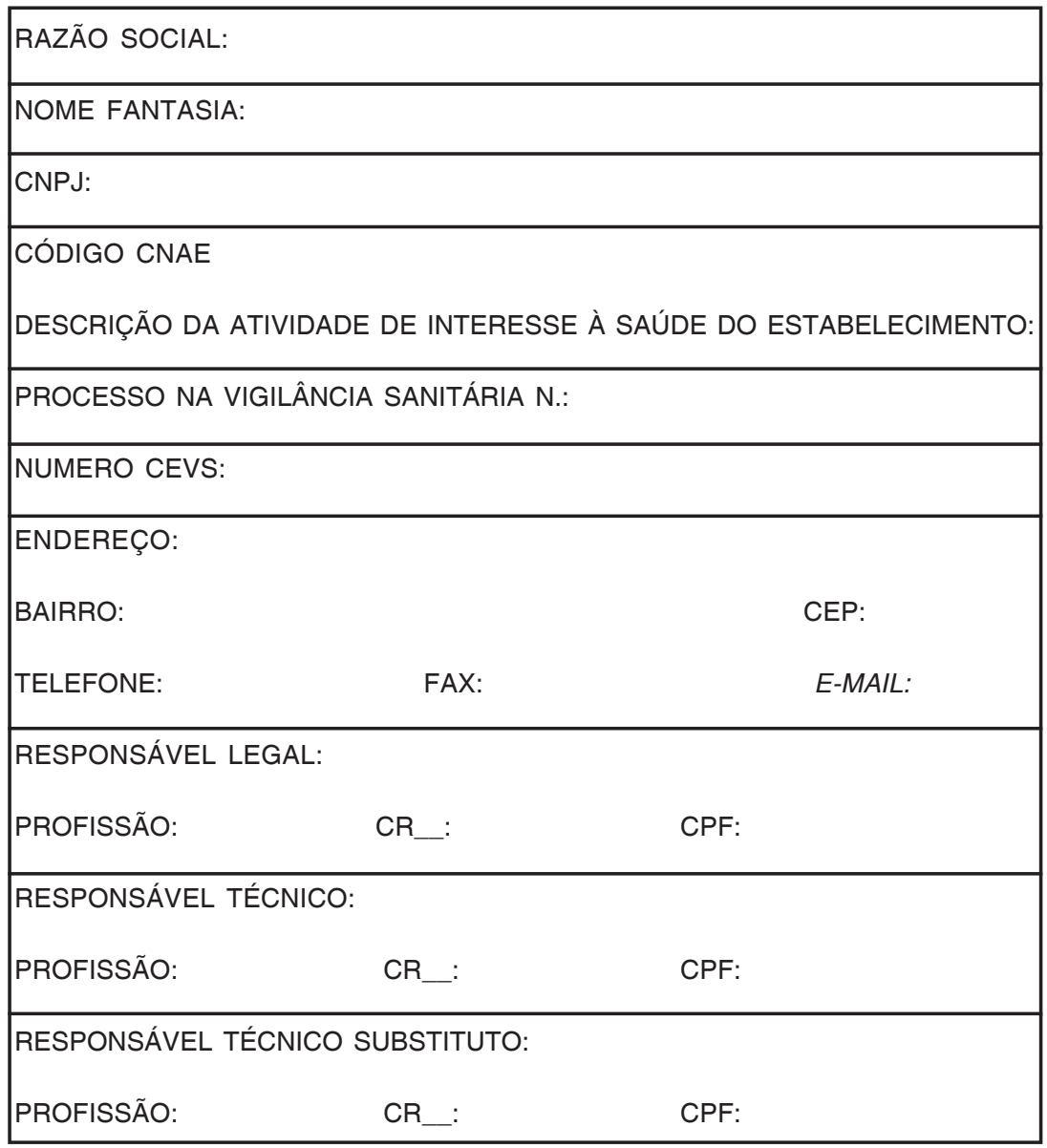

HORÁRIO DE FUNCIONAMENTO DO ESTABELECIMENTO:

INTEGRAL: $\quad$ TURNO DA MANHÃ: TURNO DA TARDE: 


\section{CARACTERIZAÇÃO DO ESTABELECIMENTO}

FOLHA 1

1) TIPO DE INSTITUIÇÃO: (Segundo LDB, art.30) PÙBLICA

PRIVADA : PARTICULAR

COMUNITÁRIA

CONFESSIONAL

FILANTRÓPICA

2) PORTE DA INSTITUIÇÃO: (Segundo Portaria MS n. 321 )

PEQUENO (até 50 crianças)

MÉDIO (51 a 100 crianças)

GRANDE (101 a 200 crianças)

3) PERFIL DA CLIENTELA ATENDIDA

\begin{tabular}{|c|c|c|c|c|c|c|c|c|c|c|}
\hline \multirow[t]{3}{*}{ TURMA } & \multirow[t]{3}{*}{ IDADE } & \multicolumn{6}{|c|}{ NÚMERO DE CRIANÇAS POR TURNO } & \multicolumn{2}{|c|}{ TOTAL } & \multirow{3}{*}{$\begin{array}{c}\text { N. DE } \\
\text { PROFISSIONAIS }\end{array}$} \\
\hline & & \multicolumn{2}{|c|}{ MANHÃ (a) } & \multicolumn{2}{|c|}{ TARDE (b) } & \multicolumn{2}{|c|}{ INTEGRAL (c) } & \multirow[t]{2}{*}{$a+c$} & \multirow[t]{2}{*}{$\mathrm{b}+\mathrm{c}$} & \\
\hline & & ATUAL & MÁX/m & ATUA & $M A ́ X / m^{2}$ & ATUAL & $\mathrm{MÁX} / \mathrm{m}^{2}$ & & & \\
\hline & & & & & & & & & & \\
\hline & & & & & & & & & & \\
\hline & & & & & & & & & & \\
\hline & & & & & & & & & & \\
\hline & & & & & & & & & & \\
\hline & & & & & & & & & & \\
\hline & & & & & & & & & & \\
\hline & & & & & & & & & & \\
\hline & & & & & & & & & & \\
\hline & & & & & & & & & & \\
\hline TOT & TAL & & & & & & & & & \\
\hline
\end{tabular}

Parâmetros estabelecidos pela Portaria MS n. 321:

BERÇÁRIO (DE 0 A 1 ANO): - máximo de 15 crianças por turma

— área mínima de 2,50 $\mathrm{m}^{2}$ por berço

— um profissional para cada 5 crianças

TURMAS DE 1 A 6 ANOS: - máximo de 20 crianças por turma

- área mínima de 2,00 $\mathrm{m}^{2}$ por criança

- um profissional para cada 10 crianças 


\begin{tabular}{|l|l|}
\hline AVALIAÇÃO DE ESTRUTURA & FOLHA 2 \\
\hline
\end{tabular}

\begin{tabular}{|c|c|c|c|c|}
\hline $\begin{array}{c}\text { ITEM DA } \\
\text { PORTARIA } \\
321 / 88\end{array}$ & LOCALIZAÇÃO & SIM & NÃO & N. A. \\
\hline $5.2 d$ & Edificação implantada em pavimento térreo? & & & \\
\hline $5.2 f$ & $\begin{array}{l}\text { Possui afastamento mínimo de } 3 \mathrm{~m} \text { em relação às } \\
\text { vias públicas e propriedades vizinhas? }\end{array}$ & & & \\
\hline $5.2 \mathrm{~h}$ & $\begin{array}{l}\text { Existe afastamento de áreas com poluição sonora } \\
\text { e do ar? }\end{array}$ & & & \\
\hline $5.2 \mathrm{~g}$ & $\begin{array}{l}\text { Existe disponibilidade de abastecimento regular de } \\
\text { água tratada, rede de luz/força e rede de esgoto e } \\
\text { águas pluviais? }\end{array}$ & & & \\
\hline
\end{tabular}

\begin{tabular}{|c|c|c|c|c|}
\hline $\begin{array}{l}\text { ITEM DA } \\
\text { PORTARIA } \\
321 / 88\end{array}$ & CIRCULAÇÃO EXTERNA & SIM & NÃO & N. A. \\
\hline $5.2 d$ & $\begin{array}{l}\text { Possui entrada principal exclusiva para crianças e } \\
\text { familiares? }\end{array}$ & & & \\
\hline $5.2 f$ & $\begin{array}{l}\text { Possui entrada secundária para o abastecimento } \\
\text { da unidade e entrada de funcionários? }\end{array}$ & & & \\
\hline $5.2 \mathrm{~h}$ & $\begin{array}{l}\text { Presença de rampa com largura mínima de } 2 \mathrm{~m} \text {, } \\
\text { declividade máxima de } 8 \% \text { e piso antiderrapante } \\
\text { em caso de desnível da entrada de crianças em } \\
\text { relação à rua? }\end{array}$ & & & \\
\hline $5.2 \mathrm{~g}$ & $\begin{array}{l}\text { Presença de estacionamento em caso de creche } \\
\text { de médio e grande porte com número de vagas de, } \\
\text { no mínimo, } 15 \% \text { da capacidade da creche? }\end{array}$ & & & \\
\hline
\end{tabular}

\begin{tabular}{|c|c|c|c|c|}
\hline $\begin{array}{c}\text { ITEM DA } \\
\text { PORTARIA } \\
321 / 88\end{array}$ & CIRCULAÇÃO INTERNA & SIM & NÃO & N. A. \\
\hline 6.2 .1 & $\begin{array}{l}\text { Ás áreas de atividades, lazer e cuidados da criança } \\
\text { estão protegidas do tráfego estranho ao serviço? }\end{array}$ & & & \\
\hline 6.2 .2 & $\begin{array}{l}\text { Os corredores de circulação interna possuem largura } \\
\text { mínima de } 1,50 \mathrm{~m} \text { e comprimento de até } 30 \mathrm{~m} ?\end{array}$ & & & \\
\hline 7.4 & $\begin{array}{l}\text { Os elementos apresentam disposição simples e } \\
\text { passagens claras e diretas? }\end{array}$ & & & \\
\hline
\end{tabular}




\section{\begin{tabular}{|l|l}
\hline AVALIAÇÃO DE ESTRUTURA — Área Física Interna & FOLHA 3 \\
\hline
\end{tabular}}

\begin{tabular}{|c|c|c|c|c|}
\hline $\begin{array}{l}\text { ITEM DA } \\
\text { PORTARIA } \\
321 / 88\end{array}$ & REQUISITOS TÉCNICOS & SIM & NÃO & N. A. \\
\hline 6.2 .1 & $\begin{array}{l}\text { Existência de boas condições ambientais quanto à } \\
\text { acústica? }\end{array}$ & & & \\
\hline 6.2 .2 & $\begin{array}{l}\text { Existência de insolação, iluminação e ventilação } \\
\text { naturais controladas de modo a permitir o necessário } \\
\text { conforto do ambiente? }\end{array}$ & & & \\
\hline 7.4 & $\begin{array}{l}\text { Possui o mínimo de } 7 \mathrm{~m}^{2} \text { de área construída por } \\
\text { criança, desconsiderados o recreio descoberto e } \\
\text { o solário? }\end{array}$ & & & \\
\hline
\end{tabular}

\begin{tabular}{|c|c|c|c|c|}
\hline $\begin{array}{l}\text { ITEM DA } \\
\text { PORTARIA } \\
\text { 321/88 }\end{array}$ & UNIDADE DE ADMINISTRAÇÃO & SIM & NÃO & N. A. \\
\hline 9.1 .1 & $\begin{array}{l}\text { Possui hall /sala de espera em recinto único ou } \\
\text { desmembrado, situado logo na entrada com área } \\
\text { mínima de } 0,20 \mathrm{~m}^{2} \text { de construção por criança? } \\
\text { POSSUI SANITÁRIOS PARA O PÚBLICO COM: }\end{array}$ & & & 册册 \\
\hline 9.1 .2 & Separação por sexo? & & & \\
\hline $9.1 .2 \mathrm{c}$ & $\begin{array}{l}\text { Anteparo na entrada de modo a impedir o devassa- } \\
\text { mento do interior? }\end{array}$ & & & \\
\hline $9.1 .2^{\mathrm{a} / \mathrm{b}}$ & $\begin{array}{l}\text { Obs.: creches de pequeno porte, área mínima de } \\
2 \mathrm{~m}^{2} \text { por sanitário, comportando } 1 \text { sanitário e } 1 \\
\text { lavatório. Nas creches de maior porte, o número } \\
\text { deve ser aumentado de acordo com o número de } \\
\text { usuários. }\end{array}$ & & & \\
\hline 9.1 .3 & $\begin{array}{l}\text { Possui secretaria em recinto único, se creche de } \\
\text { pequeno porte, com área mínima de } 0,20 \mathrm{~m}^{2} \text { de } \\
\text { construção por criança? }\end{array}$ & & & \\
\hline $9.1 .3 b$ & $\begin{array}{l}\text { Se creche de médio ou grande porte, os diversos } \\
\text { serviços prestados pela secretaria estão desmem- } \\
\text { brados em diversos ambientes? }\end{array}$ & & & \\
\hline 9.1 .4 & $\begin{array}{l}\text { Existe sala da coordenadoria com área mínima de } \\
10 \mathrm{~m}^{2} ?\end{array}$ & & & \\
\hline $9.1 .5 \mathrm{a} / \mathrm{b}$ & $\begin{array}{l}\text { Possui local para guardar equipamentos? (Pequeno } \\
\text { porte pode ser um armário e maior porte local } \\
\text { específico com área mínima de } 2 \mathrm{~m}^{2} \text { ) }\end{array}$ & & & \\
\hline
\end{tabular}




\begin{tabular}{|l|l|l|l|l|}
\hline $\begin{array}{c}\text { ITEM DA } \\
\text { PORTARIA } \\
\mathbf{3 2 1 / 8 8}\end{array}$ & UNIDADE DE ADMINISTRAÇÃO & SIM & NÃO & N. A. \\
\hline 9.1 .6 & $\begin{array}{l}\text { Se creche de médio ou grande porte, possui sala } \\
\text { de reunião com área mínima de } 20 \mathrm{~m}^{2} ?\end{array}$ & & \\
\cline { 2 - 6 } 9.1 .7 & $\begin{array}{l}\text { Existe local para depósito de material de limpeza } \\
\text { que pode ser recinto ou armário, com área mínima } \\
\text { de } 1 \mathrm{~m}^{2} ?\end{array}$ & & & \\
\hline
\end{tabular}

AVALIAÇÃO DE ESTRUTURA — Área Física Interna

FOLHA 4

\begin{tabular}{|c|c|c|c|c|}
\hline $\begin{array}{c}\text { ITEM DA } \\
\text { PORTARIA } \\
321 / 88\end{array}$ & UNIDADE DE ATENDIMENTO E CUIDADOS & SIM & NÃO & N. A. \\
\hline & $\begin{array}{l}\text { POSSUI SALA DE RECEPÇÃO E TROCA DE ROU- } \\
\text { PA PARA CRIANÇAS DE } 0 \text { A } 1 \text { ANO COM: }\end{array}$ & & & 册册 \\
\hline $9.2 .1 \mathrm{a}$ & $\begin{array}{l}\text { Área mínima de } 2 \mathrm{~m}^{2} \text { por criança, considerando-se } \\
\text { para sua utilização o máximo de } 3 \text { crianças simul- } \\
\text { taneamente? }\end{array}$ & & & \\
\hline $9.2 .1 b$ & $\begin{array}{l}\text { Comunicação direta com cada berçário, no máxi- } \\
\text { mo } 2 \text { por sala? }\end{array}$ & & & \\
\hline $9.2 .1 \mathrm{c}$ & $\begin{array}{l}\text { Bancadas altas para troca de roupa, banheirinhas para } \\
\text { os bebês, pia de despejo e lavatório para adultos? }\end{array}$ & & & \\
\hline & $\begin{array}{l}\text { POSSUI SALA DE RECEPÇÃO E TROCA DE } \\
\text { ROUPA PARA CRIANÇAS DE } 1 \text { A } 4 \text { ANOS COM: }\end{array}$ & & & \\
\hline $9.2 .2 \mathrm{a}$ & $\begin{array}{l}\text { Área mínima de } 1 \mathrm{~m}^{2} \text { por criança, com área capaz } \\
\text { de atender a } 30 \% \text { do total dessa faixa etária? }\end{array}$ & & & \\
\hline $9.2 .2 b$ & $\begin{array}{l}\text { Instalações sanitárias anexas observando as pro- } \\
\text { porções de } 1 \text { vaso sanitário e } 1 \text { lavatório para cada } \\
6 \text { crianças, } 1 \text { chuveiro para cada } 8 \text { crianças? }\end{array}$ & & & \\
\hline $9.2 .2 \mathrm{c}$ & $\begin{array}{l}\text { Acesso aos vasos sanitários e chuveiros através } \\
\text { de vestíbulo ventilado e provido de lavatório que } \\
\text { pode ser a própria sala de troca de roupa? }\end{array}$ & & & \\
\hline $9.2 .2 \mathrm{~d}$ & $\begin{array}{l}\text { Obs.: Nas creches de pequeno porte, a sala de } \\
\text { troca de roupa com sanitários anexos pode ser } \\
\text { centralizada e para as de maior porte recomenda- } \\
\text {-se que seja prevista uma para cada sala de ativi- } \\
\text { dades dessa faixa etária. }\end{array}$ & & & \\
\hline & $\begin{array}{l}\text { POSSUI SALA DE AMAMENTAÇÃO PARA AS } \\
\text { MÃES QUE PRECISAM AMAMENTAR SEUS FI- } \\
\text { LHOS COM: }\end{array}$ & 册 & & \\
\hline
\end{tabular}




\begin{tabular}{|c|c|c|c|c|}
\hline $\begin{array}{c}\text { ITEM DA } \\
\text { PORTARIA } \\
321 / 88\end{array}$ & UNIDADE DE ATENDIMENTO E CUIDADOS & SIM & NÃO & N. A. \\
\hline $9.2 .3 a$ & $\begin{array}{l}\text { Dimensão de } 1,20 \mathrm{~m}^{2} \text { por criança de } 0 \text { a } 1 \text { ano em } \\
\text { fase de amamentação? }\end{array}$ & & & \\
\hline $9.2 .3 b$ & Lavatório dotado de sabão líquido e papel toalha? & & & \\
\hline \multirow[t]{2}{*}{$9.2 .3 c$} & $\begin{array}{l}\text { Localização em elemento de fácil acesso e sem } \\
\text { alterar o trabalho com as demais crianças? }\end{array}$ & & & \\
\hline & $\begin{array}{l}\text { POSSUI CONSULTÓRIO PARA ÁREA MÉDICA, } \\
\text { PSICOPEDAGÓGICA E SOCIAL COM: }\end{array}$ & 册 & 曲册 & 䎴 \\
\hline 9.2 .4 & Área mínima de $9 \mathrm{~m}^{2}$ e dimensão linear de 2,50 m? & & & \\
\hline $9.2 .4 a$ & $\begin{array}{l}\text { Proporção de } 1 \text { consultório para cada } 100 \text { crian- } \\
\text { ças da creche? }\end{array}$ & & & \\
\hline $9.2 .4 b$ & Localizado na área de administração? & & & \\
\hline $9.2 .4 \mathrm{c}$ & Lavatório, sabão líquido e papel toalha? & & & \\
\hline
\end{tabular}

AVALIAÇÃo DE ESTRUTURA — Área Física Interna

FOLHA 5

\begin{tabular}{|c|c|c|c|c|}
\hline $\begin{array}{c}\text { ITEM DA } \\
\text { PORTARIA } \\
321 / 88\end{array}$ & UNIDADE DE ATENDIMENTO E CUIDADOS & SIM & NÃO & N. A. \\
\hline & POSSUI ENFERMARIA DE OBSERVAÇÃO COM: & 册 & & 世 \\
\hline $9.2 .5 \mathrm{a}$ & $\begin{array}{l}\text { Um berço para cada } 25 \text { crianças de } 0 \text { a } 1 \text { ano e um } \\
\text { leito para cada } 25 \text { crianças das demais idades? }\end{array}$ & & & \\
\hline $9.2 .5 \mathrm{c}$ & $\begin{array}{l}\text { Sanitário anexo com área mínima de } 3 \mathrm{~m}^{2} \text { dotado } \\
\text { de vaso sanitário, lavatório e chuveiro? }\end{array}$ & & & \\
\hline $9.2 .5 d$ & $\begin{array}{l}\text { Localizada próximo aos consultórios e sem } \\
\text { comunicação com as demais dependências }\end{array}$ & & & \\
\hline ITEM DA & UNIDADE DE ATIVIDADES E LAZER & SIM & NÃO & N. A. \\
\hline & ros & 册 & & \\
\hline $9.3 .1 \mathrm{a}$ & Área mínima de $2,50 \mathrm{~m}^{2}$ por berço? & & & \\
\hline $9.3 .1 \mathrm{~b}$ & Capacidade máxima de 15 crianças de 0 a 1 ano? & & & \\
\hline $9.3 .1 d$ & Acesso direto ao solário? & & & \\
\hline $9.3 .1 \mathrm{e}$ & $\begin{array}{l}\text { Espaçamento de } 0,50 \mathrm{~m} \text { entre os berços e } 0,50 \mathrm{~m} \\
\text { entre berços e paredes? }\end{array}$ & & & \\
\hline
\end{tabular}




\begin{tabular}{|c|c|c|c|c|}
\hline $\begin{array}{c}\text { ITEM DA } \\
\text { PORTARIA } \\
321 / 88\end{array}$ & UNIDADE DE ATIVIDADES E LAZER & $\operatorname{SIM}$ & NÃO & N. A. \\
\hline & POSSUI BERÇÁRIO COM: & 册珊 & 粗冓 & 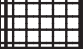 \\
\hline $9.3 .2 \mathrm{a}$ & Área mínima de 2,50 $\mathrm{m}^{2}$ por berço? & & & \\
\hline $9.3 .2 b$ & Capacidade máxima de 15 crianças de 0 a 1 ano? & & & \\
\hline $9.3 .2 \mathrm{c}$ & Acesso direto ao solário? & & & \\
\hline $9.3 .3 \mathrm{a} / \mathrm{b}$ & $\begin{array}{l}\text { Espaçamento de } 0,50 \mathrm{~m} \text { entre os berços e } 0,50 \mathrm{~m} \\
\text { entre berços e paredes? } \\
\text { POSSUI SOLÁRIO COM: }\end{array}$ & & & \\
\hline $9.3 .3 \mathrm{c}$ & $\begin{array}{l}\text { Área para atender } 30 \% \text { da capacidade do berçá- } \\
\text { rio? }\end{array}$ & & & \\
\hline $9.3 .3 d$ & $\begin{array}{l}\text { Localização anexa ao berçário e área de } 2,50 \mathrm{~m}^{2} \\
\text { por berço? }\end{array}$ & & & \\
\hline $9.3 .3 e$ & $\begin{array}{l}\text { Obs. o solário pode situar-se em varanda aberta } \\
\text { ou gramado para onde devem ser transportados } \\
\text { os berços ou serem utilizados colchões no piso e } \\
\text { lonas impermeáveis sobre os gramados, a fim de } \\
\text { permitir banhos de sol às crianças. } \\
\text { POSSUI SALA DE ATIVIDADES COM: }\end{array}$ & & & \\
\hline \multirow[t]{7}{*}{9.3 .4} & $\begin{array}{l}\text { Acomodação de no máximo } 20 \text { crianças por unida- } \\
\text { de e área mínima de } 2 \mathrm{~m}^{2} \text { por criança? }\end{array}$ & & & \\
\hline & Acesso direto para o exterior? & & & \\
\hline & $\begin{array}{l}\text { Equipamento apropriado para a faixa etária a que } \\
\text { se destina? }\end{array}$ & & & \\
\hline & $\begin{array}{l}\text { Armário ou depósito anexo para a guarda do mate- } \\
\text { rial? }\end{array}$ & & & \\
\hline & POSSUI SALA DE REPOUSO COM: & & & \\
\hline & $\begin{array}{l}\text { Área mínima de } 2,50 \mathrm{~m}^{2} \text { por criançada faixa etária } \\
\text { de } 1 \text { a } 2 \text { anos com acomodações individuais para } \\
\text { repouso? }\end{array}$ & & & \\
\hline & $\begin{array}{l}\text { Obs. nas creches de pequeno porte pode ser usa- } \\
\text { da a própria sala de atividades. }\end{array}$ & & & \\
\hline
\end{tabular}




\begin{tabular}{|l|c|}
\hline AVALIAÇÃO DE ESTRUTURA — Área Física Interna & FOLHA 6 \\
\hline
\end{tabular}

\begin{tabular}{|c|c|c|c|c|}
\hline \multirow[t]{2}{*}{$\begin{array}{c}\text { ITEM DA } \\
\text { PORTARIA } \\
321 / 88\end{array}$} & UNIDADE DE ATIVIDADES E LAZER & $\operatorname{SIM}$ & NÃO & N. A. \\
\hline & $\begin{array}{l}\text { POSSUI REFEITÓRIO PARA ATENDIMENTO DE } \\
\text { CRIANÇAS DE } 2 \text { A } 6 \text { ANOS COM: }\end{array}$ & 䎴地 & 㐩冊 & \\
\hline $9.3 .5 b$ & Área mínima de $1,20 \mathrm{~m}^{2}$ por criança? & & & \\
\hline $9.3 .5 \mathrm{c}$ & Máximo de 2 grupos de revezamento? & & & \\
\hline \multirow[t]{2}{*}{$9.3 .5 d$} & Comunicação direta com a cozinha? & & & \\
\hline & POSSUI RECREIO COBERTO COM: & & & \\
\hline \multirow[t]{2}{*}{9.3 .6} & $\begin{array}{l}\text { Área mínima de } 2 \mathrm{~m}^{2} \text { por criança da faixa etária de } 1 \\
\text { a } 6 \text { anos? Obs.: nas creches de pequeno porte o } \\
\text { recreio coberto pode ser a própria sala de atividades }\end{array}$ & & & \\
\hline & POSSUI RECREIO DESCOBERTO COM: & & 挥 & \\
\hline $9.3 .7 a$ & $\begin{array}{l}\text { Área mínima de } 4 \mathrm{~m}^{2} \text { por criança da faixa etária de } \\
1 \text { a } 6 \text { anos? }\end{array}$ & & & \\
\hline 9.3.7b. & Comunicação direta com a sala de atividades? & & & \\
\hline $9.3 .7 \mathrm{c}$ & $\begin{array}{l}\text { Área verde e equipamentos de recreação como } \\
\text { balanços, escorregador, tanque de areia etc.? }\end{array}$ & & & \\
\hline \multirow{3}{*}{$\begin{array}{c}\text { ITEM DA } \\
\text { PORTARIA } \\
321 / 88 \\
\end{array}$} & UNIDADE DE APOIO & SIM & NÃO & N. A. \\
\hline & & & & \\
\hline & $\begin{array}{l}\text { POSSUI LACTÁRIO PARA ATENDIMANTO DE } \\
\text { CRIANÇAS DA FAIXA ETÁRIA DE } 0 \text { A } 1 \text { ANO COM: }\end{array}$ & & & \\
\hline $9.4 .1 \mathrm{a}$ & $\begin{array}{l}\text { Locais separados para recepção e lavagem das ma- } \\
\text { madeiras e para preparo, esterilização e distribuição }\end{array}$ & & & \\
\hline $9.4 .1 b$ & $\begin{array}{l}\text { Área mínima de } 0,20 \mathrm{~m}^{2} \text { de construção por criança } \\
\text { de } 0 \text { a } 1 \text { ano? }\end{array}$ & & & \\
\hline \multirow[t]{2}{*}{$9.4 .1 \mathrm{c}$} & Previsão de equipamento adequado? & & & \\
\hline & $\begin{array}{l}\text { POSSUUI COZINHA PARA PREPARO DA ALIMEN- } \\
\text { TAÇÃO DAS CRIANÇAS DE } 1 \text { A } 6 \text { ANOS COM: }\end{array}$ & & & \\
\hline $9.4 .2 \mathrm{a}$ & Área mínima de $0,40 \mathrm{~m}^{2}$ de construção por criança? & & & \\
\hline $9.4 .2 b$ & $\begin{array}{l}\text { Localização de fácil acesso ao refeitório e à des- } \\
\text { pensa? }\end{array}$ & & & \\
\hline $9.4 .2 \mathrm{c}$ & Previsão de equipamentos adequados? & & & \\
\hline \multirow{2}{*}{$\begin{array}{l}\text { Lei Est. } \\
10.083 \\
\text { art. } 144\end{array}$} & Teto com forro adequado e luminárias protegidas & & & \\
\hline & $\begin{array}{l}\text { Lixo acondicionado em coletores impermeáveis com } \\
\text { tampa de acionamento por pedais e dotados de } \\
\text { sacos plásticos }\end{array}$ & & & \\
\hline
\end{tabular}




\section{AVALIAÇÃO DE ESTRUTURA — Área Física Interna \\ FOLHA 7}

\begin{tabular}{|c|c|c|c|c|}
\hline $\begin{array}{l}\text { ITEM DA } \\
\text { RESOLUÇÃO } \\
216 / 04\end{array}$ & UNIDADE DE APOIO & SIM & NÃO & N. A. \\
\hline & $\begin{array}{l}\text { POSSUI COZINHA PARA PREPARO DA ALIMEN- } \\
\text { TAÇÃO DAS CRIANÇAS DE } 1 \text { A } 6 \text { ANOS COM: }\end{array}$ & 册轨 & 犕 & 烠册 \\
\hline 4.1 .1 & $\begin{array}{l}\text { Edificação e instalações projetadas de forma a pos- } \\
\text { sibilitar fluxo ordenado e sem cruzamentos em to- } \\
\text { das as etapas de preparação de alimentos? }\end{array}$ & & & \\
\hline 4.1 .2 & $\begin{array}{l}\text { Dimensionamento da edificação e das instalações } \\
\text { compatível com todas as operações? }\end{array}$ & & & \\
\hline 4.1 .3 & $\begin{array}{l}\text { Piso, parede e teto possuem revestimento liso, im- } \\
\text { permeável e lavável? }\end{array}$ & & & \\
\hline 4.1 .3 & $\begin{array}{l}\text { Piso, parede e tetos mantidos íntegros, conserva- } \\
\text { dos, livres de rachaduras, trincas, goteiras, vaza- } \\
\text { mentos, dentre outros? }\end{array}$ & & & \\
\hline 4.1 .4 & $\begin{array}{l}\text { Portas e aberturas externas providas de telas mili- } \\
\text { métricas removíveis para limpeza? }\end{array}$ & & & \\
\hline 4.1 .6 & $\begin{array}{l}\text { Caixas de gordura e de esgoto com dimensões } \\
\text { compatíveis, localizadas fora da área de prepara- } \\
\text { ção e armazenamento dos alimentos? }\end{array}$ & & & \\
\hline 4.1.7 & $\begin{array}{l}\text { Áreas internas e externas do elemento estão livres } \\
\text { de objetos em desuso ou estranhos ao ambiente e } \\
\text { sem a presença de animais? }\end{array}$ & & & \\
\hline 4.1 .8 & $\begin{array}{l}\text { Iluminação da área de preparação proporciona vi- } \\
\text { sualização que permita realizar as atividades sem } \\
\text { comprometer a higiene e as características senso- } \\
\text { riais dos alimentos? }\end{array}$ & & & \\
\hline 4.1 .8 & $\begin{array}{l}\text { As luminárias estão protegidas contra explosão e } \\
\text { quedas acidentais? }\end{array}$ & & & \\
\hline 4.1 .9 & $\begin{array}{l}\text { Instalações elétricas estão embutidas ou protegi- } \\
\text { das em tubulações externas e íntegras? }\end{array}$ & & & \\
\hline 4.1 .10 & $\begin{array}{l}\text { A ventilação garante renovação do ar sem que o } \\
\text { fluxo incida diretamente sobre os alimentos? }\end{array}$ & & & \\
\hline 4.1.14 & $\begin{array}{l}\text { Lavatório exclusivo para higiene das mãos na área } \\
\text { de manipulação dotadas de sabonete líquido inodo- } \\
\text { ro antisséptico e toalhas de papel? }\end{array}$ & & & \\
\hline 4.2 .1 & $\begin{array}{l}\text { Instalações, equipamentos, móveis e utensílios em } \\
\text { condições higiênico-sanitárias apropriadas? }\end{array}$ & & & \\
\hline 4.2 .5 & $\begin{array}{l}\text { Produtos saneantes utilizados estão regularizados } \\
\text { pelo Ministério da Saúde? }\end{array}$ & & & \\
\hline
\end{tabular}




\section{\begin{tabular}{|l|l}
\hline AVALIAÇÃO DE ESTRUTURA — Área Física Interna & FOLHA 8 \\
\hline
\end{tabular}}

\begin{tabular}{|c|c|c|c|c|}
\hline $\begin{array}{l}\text { ITEM DA } \\
\text { RESOLUÇÃO } \\
216 / 04\end{array}$ & UNIDADE DE APOIO & SIM & NÃO & N. A. \\
\hline 4.3 .1 & $\begin{array}{l}\text { Edificação, instalações, móveis, equipamentos e } \\
\text { utensílios são livres de vetores e pragas urbanas? }\end{array}$ & & & \\
\hline 4.5 .2 & $\begin{array}{l}\text { Coletores de resíduos das áreas de preparação e } \\
\text { armazenamento de alimentos são dotados de tampa } \\
\text { sem acionamento manual? }\end{array}$ & & & \\
\hline 4.5 .3 & $\begin{array}{l}\text { Resíduos frequentemente coletados e estocados } \\
\text { em local fechado e isolado da área de preparação e } \\
\text { armazenamento dos alimentos? }\end{array}$ & & & \\
\hline 4.6 .1 & $\begin{array}{l}\text { Controle de saúde dos manipuladores realizado e } \\
\text { registrado? }\end{array}$ & & & \\
\hline 4.6 .6 & $\begin{array}{l}\text { Manipuladores usam cabelos presos e protegidos } \\
\text { por rede ou touca, usam unhas curtas e retiram } \\
\text { objetos de adorno pessoal durante a manipulação? }\end{array}$ & & & \\
\hline 4.7 .5 & $\begin{array}{l}\text { Armazenamento de alimentos em local limpo e } \\
\text { organizado, devidamente identificados e utilizados } \\
\text { respeitando o prazo de validade? }\end{array}$ & & & \\
\hline 4.7.6 & $\begin{array}{l}\text { Matérias-primas, ingredientes e embalagens } \\
\text { armazenados sem contato direto com piso e parede, } \\
\text { em suporte de material liso, resistente, impermeável } \\
\text { e lavável? }\end{array}$ & & & \\
\hline 4.8 .18 & $\begin{array}{l}\text { O alimento preparado armazenado sob refrigeração } \\
\text { ou congelamento tem identificação com designação, } \\
\text { data de preparo e prazo de validade? }\end{array}$ & & & \\
\hline 4.12 .2 & $\begin{array}{l}\text { O responsável pelas atividades de manipulação dos } \\
\text { alimentos foi comprovadamente submetido a curso } \\
\text { de capacitação? }\end{array}$ & & & \\
\hline
\end{tabular}




\begin{tabular}{|c|c|c|c|c|}
\hline $\begin{array}{l}\text { ITEM DA } \\
\text { PORTARIA }\end{array}$ & UNIDADE DE APOIO & SIM & NÃO & N. A. \\
\hline & $\begin{array}{l}\text { POSSUI DESPENSA PARA GUARDA E ESTOCA- } \\
\text { GEM DE MANTIMENTOS PARA TODAS AS CRIAN- } \\
\text { ÇAS DA CRECHE COM: }\end{array}$ & & & \\
\hline $9.4 .3 a$ & Área mínima correspondente a $40 \%$ da cozinha? & & & \\
\hline $9.4 .3 b$ & $\begin{array}{l}\text { Equipamento adequado como balança, mesa, es- } \\
\text { trado, escada, prateleiras, refrigerador e freezer? }\end{array}$ & & & \\
\hline $9.4 .3 \mathrm{c}$ & $\begin{array}{l}\text { Localização de fácil acesso pela entrada de servi- } \\
\text { ço considerando-se a descarga de mantimentos? }\end{array}$ & & & \\
\hline & $\begin{array}{l}\text { POSSUI LAVANDERIA PARA ATENDER, NO MÍ- } \\
\text { NIMO, AO FORNECIMENTO DE ROUPA LIMPA } \\
\text { DA INSTITUIÇÃO E DE ALGUMA EMERGÊNCIA } \\
\text { DE TODAS AS CRIANÇAS COM: }\end{array}$ & & & \\
\hline $9.4 .4 \mathrm{a}$ & Área mínima de $0,20 \mathrm{~m}^{2}$ de construção por criança? & & & \\
\hline $9.4 .4 \mathrm{~b}$ & $\begin{array}{l}\text { Equipamento adequado como máquina de lavar e } \\
\text { secadora? }\end{array}$ & & & \\
\hline & POSSUI ROUPARIA SENDO: & & & \\
\hline $9.4 .5 \mathrm{a}$ & $\begin{array}{l}\text { Nas creches de pequeno porte no mínimo um ar- } \\
\text { mário? }\end{array}$ & & & \\
\hline $9.4 .5 b$ & $\begin{array}{l}\text { Nas creches de maior porte sala anexa à lavande- } \\
\text { ria com área mínima correspondendo a } 40 \% \text { da } \\
\text { área da lavanderia? }\end{array}$ & & & \\
\hline & ALMOXARIFADO & & & \\
\hline 9.4 .7 & $\begin{array}{l}\text { Possui almoxarifado com área mínima de } 0,40 \mathrm{~m}^{2} \text { de } \\
\text { construção por criança de todas as faixas etárias? }\end{array}$ & & & \\
\hline & POSSUI VESTIÁRIO PARA FUNCIONÁRIOS COM: & & & 册 \\
\hline 9.4 .8 & Área mínima de $0,50 \mathrm{~m}^{2}$ por funcionário? & & & \\
\hline $9.4 .8 \mathrm{c}$ & $\begin{array}{l}\text { Vasos sanitários e lavatórios na proporção de } 1 \\
\text { para cada } 5 \text { pessoas? }\end{array}$ & & & \\
\hline $9.4 .8 \mathrm{~d}$ & $25 \%$ masculino e $75 \%$ feminino? & & & \\
\hline
\end{tabular}




\begin{tabular}{|c|c|c|c|c|}
\hline $\begin{array}{l}\text { ITEM DA } \\
\text { PORTARIA }\end{array}$ & TODAS AS UNIDADES & SIM & NÃO & N. A. \\
\hline & TETOS, PAREDES E PISOS COM: & $\mathrm{H}^{+}+$ & 粗 & 艮 \\
\hline 10.1.a & $\begin{array}{l}\text { Material resistente, de fácil limpeza e adequado ao } \\
\text { clima? }\end{array}$ & & & \\
\hline 10.1.b & $\begin{array}{l}\text { Ausência de tubulação exposta em áreas como } \\
\text { berçário, lactário, cozinha e refeitório? }\end{array}$ & & & \\
\hline $10.1 \mathrm{c}$ & $\begin{array}{l}\text { Pisos sujeitos à lavagem constante revestidos de } \\
\text { material resistente à água e soluções germicidas? }\end{array}$ & & & \\
\hline $10.1 d$ & $\begin{array}{l}\text { Áreas de trabalho molhadas com piso de superfície } \\
\text { antiderrapante? }\end{array}$ & & & \\
\hline $10.1 f$ & Pintura feita com tinta plástica lavável? & & & \\
\hline $10.1 \mathrm{e} / \mathrm{g}$ & $\begin{array}{l}\text { Ausência de frestas e saliências que possam } \\
\text { abrigar insetos, roedores e sujeiras? }\end{array}$ & & & \\
\hline $10.2 b$ & Pintura de cores claras e alegres? & & & \\
\hline $\begin{array}{l}\text { Lei } \\
\text { Est. } 10.083 \\
\text { Art. } 144\end{array}$ & Todos os ralos com tampa do tipo escamoteável? & & & \\
\hline & ESQUADRIAS: & & & 乗覀 \\
\hline 11.a & $\begin{array}{l}\text { Janelas com condições adequadas à segurança } \\
\text { das crianças? }\end{array}$ & & & \\
\hline $11 . c$ & $\begin{array}{l}\text { Portas dos banheiros das crianças sem fechaduras, } \\
\text { podendo ser utilizado o tipo vai e vem? }\end{array}$ & & & \\
\hline 11.d & $\begin{array}{l}\text { Janelas teladas em berçários, salas de repouso, } \\
\text { lactário, despensa, cozinha e lavanderia? }\end{array}$ & & & \\
\hline 11.e & $\begin{array}{l}\text { Vidros de portas ou painéis que chegam até } 0,50 \mathrm{~m} \\
\text { do piso do tipo não estilhaçável? }\end{array}$ & & & \\
\hline
\end{tabular}




\begin{tabular}{|c|c|c|c|c|}
\hline $\begin{array}{c}\text { ITEM DA } \\
\text { LEGISLAÇÃO }\end{array}$ & RELAÇÃO DE PESSOAL MÍNIMO E FORMAÇÃO & SIM & NÃO & N. A. \\
\hline $\begin{array}{l}\text { Res. } 44 / \text { SES } \\
\text { Item } 10\end{array}$ & 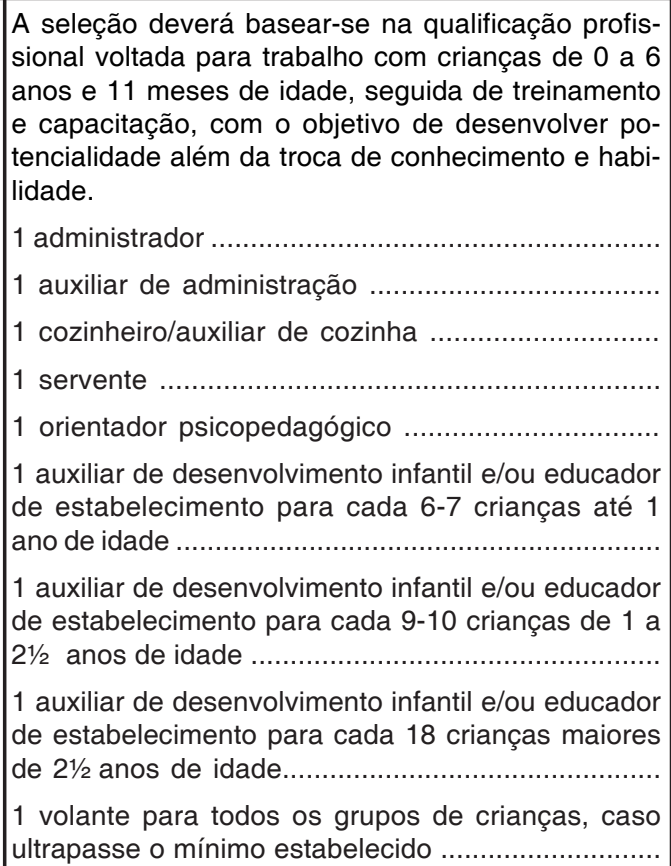 & & & \\
\hline $\begin{array}{l}\text { Res. 44/SES } \\
\text { Item } 3\end{array}$ & \multirow[b]{2}{*}{$\begin{array}{l}\text { Obs.: docentes da Educação Infantil (0 a } 6 \text { anos) } \\
\text { com formação mínima em nível médio na modalidade } \\
\text { Normal }\end{array}$} & & & \\
\hline LDB art. 62 & & & & \\
\hline
\end{tabular}


AVALIAÇÃO DE ESTRUTURA — Documentação

FOLHA 12

\begin{tabular}{|c|c|c|c|c|}
\hline $\begin{array}{c}\text { ITEM DA } \\
\text { LEGISLAÇÃO }\end{array}$ & RELAÇÃO DE DOCUMENTOS APRESENTADOS & SIM & NÃO & N. A. \\
\hline $\begin{array}{l}\text { Res.44/SES } \\
\text { Item } 3 \\
\text { Item } 9,2 \\
\text { Item } 11.5 \\
\\
\\
\\
\text { Lei Est. } \\
10.083 \\
\text { art. } 144\end{array}$ & 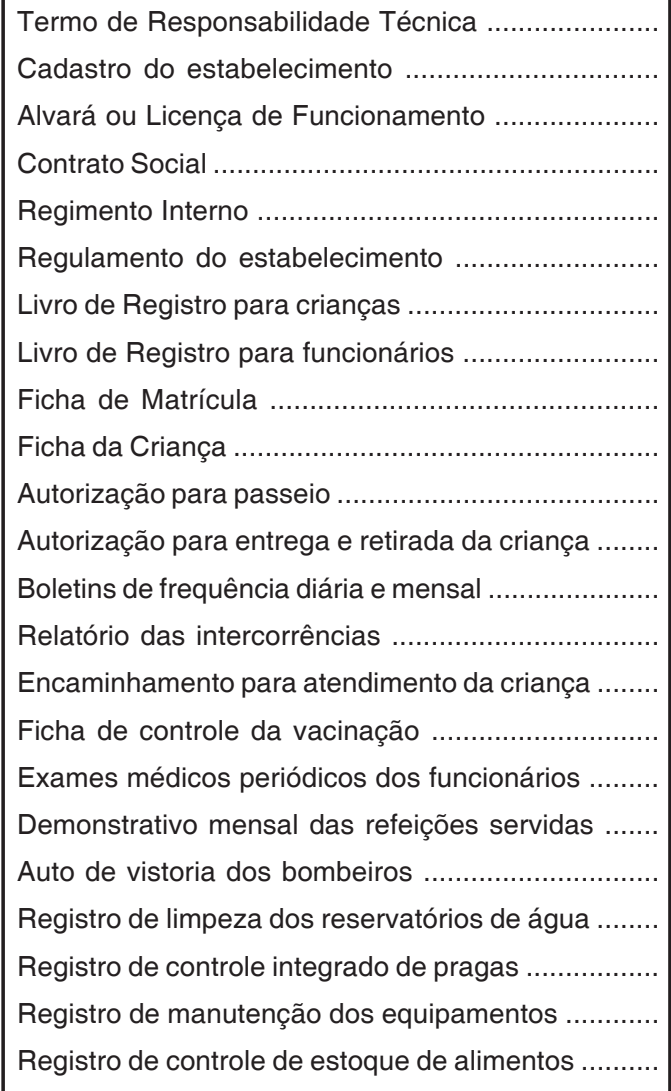 & & & \\
\hline
\end{tabular}


AGÊNCIA NACIONAL DE VIGILÂNCIA SANITÁRIA. Resolução RDC n. 216, de 15 de setembro de 2004. Dispões sobre Regulamento Técnico de Boas Práticas para Serviços de Alimentação. DOU - Diário Oficial da União; Poder Executivo, de 16 de setembro de 2004.

BRASIL. Lei n. 9.394, de 20 de dezembro de 1996. Estabelece as diretrizes e bases da educação nacional. DOU - Diário Oficial da União. Brasília, DF, 23 de dezembro de 1996. p. 27833-41.

MINISTÉRIO DA SAÚDE, Ministério da Educação. Portaria Interministerial n. 1.010, de 8 de maio de 2006. Institui as diretrizes para a Promoção da Alimentação saudável nas Escolas de educação infantil, fundamental e nível médio das redes públicas e privadas, em âmbito nacional. Brasília, DF. DOU — Diário Oficial da União, 9 de maio de 2006.

MINISTÉRIO DA SAÚDE. Portaria n. 321, de 26 de maio de 1988. Aprova as normas e os padrões mínimos, que com esta baixam, destinados a disciplinar a construção, instalação e funcionamento de creches, em todo o território nacional. DOU - Diário Oficial da União, 9 setembro de 1988.

SÃO PAULO (Estado). Lei n. 10.083, de 23 de setembro de 1998. Dispõe sobre o Código Sanitário do Estado. Diário Oficial da União, Seção I, São Paulo, 24 de setembro de 1998.

SECRETARIA DE ESTADO DA SAÚDE DE SÃO PAULO. Resolução SS n. 44, de 30 de janeiro de 1992. Aprovar a Norma Técnica para Creches e Estabelecimentos Congêneres. DOU — Diário Oficial do Estado de São Paulo, de 31 de janeiro de 1992. 